\title{
Inhaltsübersicht
}

Seite

Geleitwort ....................... VII

Vorwort ..................... IX

Inhaltsverzeichnis ................. XV

Abkürzungsverzeichnis ................... LXXXI

Teil 1

Rz. Seite

Funktion und Bedeutung der Verträge im Rechtssystem

(Heussen) ........... 1 1

Teil 2

Vertragsmanagement

(Heussen)

1 Vertragsplanung........................ 144

2 Vertragsdesign ........................... $217 \quad 119$

3 Vertragsverhandlung ....................... 368190

4 Vertragsdurchführung. . . . . . . . . . . . . . . . . 635337

5 Vertragscontrolling......................6686 365

Teil 3

Austauschverträge

(Imbeck)

1 Einführung.......................... 12371

2 Vertragsanbahnung. .................... 13376

3 Vertragsinhalt........................... 101410

4 Vertragsdurchführung. . . . . . . . . . . . . . . . 333501

\section{Teil 4}

Gesellschaftsrechtliche Verträge - Basischeckliste und Kommentierung mit Einzelformulierungsvorschlägen

(Wegmann/von dem Knesebeck)

1 Vorbereitung von Gesellschaftsverträgen und Konzepten . 1507 
Rz. Seite

2 Allgemeine Gestaltungsfragen für alle Gesellschaftsverträge .................... $62 \quad 528$

3 Gestaltungsfragen bei einzelnen Gesellschaftsverträgen . . 229582

4 Vertragsabschluss........................ 572705

5 Vertragsdurchführung. . . . . . . . . . . . . . . . . . . . 574707

\section{Teil 5}

Vertragsgestaltung und Steuern

(Meven)

1 Einführung.......................... 1 1 721

2 Vertragsplanung........................... 19727

3 Austauschverträge .................... 30732

4 Gesellschaftsrechtliche Verträge ............... 82753

5 Steuerrechtliches Vertrags-Controlling . . . . . . . . . . . . 200797

\section{Teil 6}

Vertragsenglisch

(Pischel) ............ 1800

\section{Teil 7}

Außergerichtliche Konfliktbeilegung Institutionen und Verfahren im In- und Ausland

\section{Teil 8}

Verhandeln in Brüssel

(Williamson)

1 Einleitung. . . . . . . . . . . . . . . . . . . . . . 1869

2 Besonderheiten der Interessenvertretung und des

Verhandelns auf EU-Ebene . . . . . . . . . . . . . . . 7871

3 Verhandeln mit der Europäischen Kommission in ihrer Funktion als Vollzugsbehörde ................. $12 \quad 873$

4 Verhandeln mit den europäischen Institutionen im Gesetzgebungsverfahren. . . . . . . . . . . . . . . 125908 
Inhaltsübersicht

Rz. Seite

5 Verträge mit den europäischen Institutionen . . . . . . . . . 166922

6 Schlussfolgerungen. . . . . . . . . . . . . . . . . . . . . 170923

7 Überblick. . . . . . . . . . . . . . . . . . . . . . . . . 173924

Teil 9

Verhandeln im Ausland

9.1

Verhandeln in den USA

(Kochinke)

1 Einführung: A Deal is Not a Deal. . . . . . . . . . . . . . . . 1929

2 Vertragsmanagement.................... 8932

3 Anhang........................... 152980

9.2

Verhandeln in Russland

(Schwarz)

1 Einführung-Der ferne Nachbar . . . . . . . . . . . . 1983

2 Vertragsmanagement ......................... 9989

3 Anhang.......................... 991021

9.3

Verhandeln in China

(Pattloch) ........... 11025

9.4

Verhandeln in Japan

(Tanaka) ............ 11083

9.5

Verhandeln in Brasilien

(Curschmann)

1 Einführung........................ 11113

2 Vertragsplanung....................... 6 1120

3 Vertragsdesign ........................... 191125

4 Vertragsverhandlung ... . . . . . . . . . . . . . . . . . . 261129 
Rz. Seite

5 Vertragsdurchführung. . . . . . . . . . . . . . . . . 411138

6 Vertragscontrolling. . . . . . . . . . . . . . . . . . . 441142

7 Schlusswort ......................... 461144

9.6

Verhandeln in der Türkei

(Keki)

1 Einführung........................ 11145

2 Vertragsmanagement .................. 331158

\section{7}

Verhandeln in Indien

(Luthra)

1 Einführung....................... 11181

2 Vertragsmanagement...................... 141188

Teil 10

Qualitätsmanagement von Vertragsprojekten Typische Fehler von Managern im Umgang mit ihren Beratern aus Sicht des Beraters

(Malik)

\section{Teil 11}

\section{Checklisten}

\section{1}

Checklisten für Austauschverträge

(Pischel//unker) .......... 11225

\section{2}

Checklisten für Gesellschaftsverträge

(Knigge) ........... 11251

Verzeichnis der Autoren . . . . . . . . . . . . . . . . . . . 1291

Sachregister . . . . . . . . . . . . . . . . . . . . . . . . . . . . 1297 


\section{Inhaltsverzeichnis}

Seite

Geleitwort ...................... VII

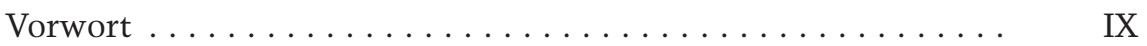

Inhaltsübersicht $\ldots \ldots \ldots \ldots \ldots \ldots \ldots \ldots \ldots \ldots \ldots$ XI

Abkürzungsverzeichnis ................... LXXXI

\section{Teil 1}

\section{Funktion und Bedeutung der Verträge im Rechtssystem}

(Heussen)

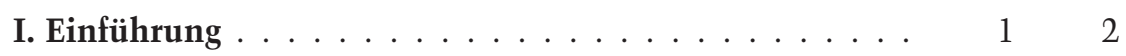

1. Verträge, Gesetze und soziale Regeln. . . . . . . . . 112

a) Geben und Nehmen, Vertrauen und Risikosteuerung $\quad \begin{array}{lll}1 & 2\end{array}$

b) Internationale Rechtskulturen . . . . . . . . . . . 3a 4

aa) Netzwerke und Hierarchien . . . . . . . . . 3a 4

bb) Der gesetzliche Rahmen in unterschiedlichen Rechtskulturen .............. 3b 5

cc) Verträge als private Gesetze . . . . . . . . . . . . . . $8 \quad 7$

2. Risiken und Risikoprognosen . . . . . . . . . . . . . . $13 \quad 9$

a) Risiko und Vertrauen . . . . . . . . . . . . . . . . . . $13 \quad 9$

b) Wesentliche Risikofaktoren . . . . . . . . . . . . 13a 10

c) Risikoprognosen . . . . . . . . . . . . . . . . . . . . . $16 \quad 12$

3. Verhandeln als soziales Ritual . . . . . . . . . . . . . . $18 \quad 12$

II. Statisches und dynamisches Vertragsverständnis . . . $21 \quad 13$

III. Komplexität, Strategie und Taktik . . . . . . . . . . . . $29 \quad 16$

1. Verträge und vernetztes Denken . . . . . . . . . . . . . $29 \quad 29$

2. Strategie, Taktik und Führung. . . . . . . . . . . . . $35 \quad 35$

a) Verbindungen und Gegensätze . . . . . . . . . . . . . $35 \quad 35$

b) Strategie . . . . . . . . . . . . . . . . . . . . $37 \quad 20$

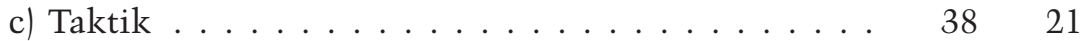

d) Führung . . . . . . . . . . . . . . . . 46a 23

IV. Vertragsmanagement . . . . . . . . . . . . . . . . . . $47 \quad 24$

1. Vertragsplanung . . . . . . . . . . . . . . . . . . . $59 \quad 28$

2. Vertragsdesign . . . . . . . . . . . . . . . . . . . . $60 \quad 29$

a) Begriff . . . . . . . . . . . . . . . . . . . 60a 29

b) Vorgehen. . . . . . . . . . . . . . . . . . . . . . . . . 60b 29

c) International einheitliche Module . . . . . . . . . . 60b 30 
3. Vertragsverhandlungen . . . . . . . . . . . . . . $61 \quad 31$

4. Vertragsdurchführung . . . . . . . . . . . . . . . . . . $72 \quad 35$

5. Vertragscontrolling . . . . . . . . . . . . . $74 \quad 35$

6. Zwölf Grundregeln des Vertragsmanagements . . . . $\quad 75 \quad 35$

V. Macht, Recht und Willkür . . . . . . . . . . . . . . . $76 \quad 37$

VI. Entscheidungen und Emotionen . . . . . . . . . . . . . $80 \quad 38$

VII. Stabilität und Anpassungsfähigkeit . . . . . . . . . . . $81 \quad 39$

Teil 2

Vertragsmanagement

(Heussen)

\section{Vertragsplanung}

I. Strategie und Taktik . . . . . . . . . . . . . . . . . . . . 14

1. Vertragsstrategie . . . . . . . . . . . . . . . . . . . . 144

2. Vertragstaktik . . . . . . . . . . . . . . . . $12 \quad 48$

3. Grenzen der Taktik . . . . . . . . . . . . . . . . . . 1951

4. Führung . . . . . . . . . . . . . 20a 51

II. Planungsfaktoren . . . . . . . . . . . . . . . . . . . . $21 \quad 52$

1. Informationen . . . . . . . . . . . . . . . . . . . $24 \quad 54$

a) Informationen geben . . . . . . . . . . . . . . . $28 \quad 55$

b) Informationen nehmen . . . . . . . . . . . . . $30 \quad 55$

c) Informationen prüfen und aktualisieren . . . . . . $31 \quad 55$

d) Einfluss auf das Vertragsmanagement . . . . . . . . . $33 \quad 56$

2. Machtverhältnisse und Beziehungen . . . . . . . . $35 \quad 56$

3. Zeitrahmen und Prioritäten . . . . . . . . . . . . $39 \quad 58$

4. Finanzielle Mittel . . . . . . . . . . . . . . . . . . . $46 \quad 60$

5. Einsatz von Projektteams . . . . . . . . . . . . . . $50 \quad 61$

6. Berater. . . . . . . . . . . . . . . . $53 \quad 62$

a) Beratungsgebiete ................. . . $53 \quad 62$

b) Auswahl von Beratern . . . . . . . . . . . . . . . . $60 \quad 65$

c) Beraterverträge . . . . . . . . . . . . . . . . . $61 \quad 65$

d) Zusammenarbeit beim Vertragsmanagement . . . $66 \quad 67$

aa) Vereinbarung von Funktion, Rolle und

Tätigkeitsumfang . . . . . . . . . . . . . $66 \quad 67$

bb) Grundregeln für die Zusammenarbeit . . . . . . $\quad 71 \quad 69$ 
e) Krisensituationen . . . . . . . . . . . . . . . . . $75 \quad 71$

f) Haftung von Beratern . . . . . . . . . . . . . . . 7972

aa) Haftung gegenüber dem Auftraggeber . . . . . . . $80 \quad 73$

bb) Haftung gegenüber Dritten . . . . . . . . . . . . . 8374

cc) Beweislast, Schaden und Verjährung . . . . . . . . $85 \quad 75$

dd) Sekundärhaftung. . . . . . . . . . . . . . . . . $88 \quad 75$

ee) Haftung des Beraters für eingeschaltete Dritte . . $90 \quad 9076$

g) Beratung im internationalen Umfeld . . . . . . . . . 91a 76

7. Kommunikation . . . . . . . . . . . . . . . . . . . . 9297

8. Entschlossenheit . . . . . . . . . . . . . . . $98 \quad 78$

9. Feste Strukturen und Flexibilität . . . . . . . . . . . . . . $104 \quad 80$

a) Auffangplanung. . . . . . . . . . . . . . . . . . . . . . $106 \quad 80$

b) Vertragskonzeption . . . . . . . . . . . . . . . . . . $107 \quad 81$

c) Flexible Regelungen . . . . . . . . . . . . . . . . . . . . $110 \quad 81$

d) Änderungsvereinbarungen . . . . . . . . . . . . . . . . . 11583

10. Störfaktoren . . . . . . . . . . . . . . . . . . . . . . . . . . 11984

III. Risikobewertung . . . . . . . . . . . . . . . . . . . . . . . $127 \quad 86$

IV. Zusammenarbeit zwischen Managern, Unternehmensjuristen und Rechtsanwälten . . . . . . . . . . . . . . . . 13790

1. Rechtsfragen im Unternehmen . . . . . . . . . . . . . . 1379

a) Risikomanagement . . . . . . . . . . . . . . . . . . . 13990

b) Manager, Unternehmensjuristen und Rechtsanwälte $\quad 14191$

2. Rechtsmanagement in der Aufbauorganisation . . . . . . 15095

a) Tatsachen und Rechtsfragen . . . . . . . . . . . . . . 15095

b) Aufgabenverteilung nach Servicegesichtspunkten . . 15596

3. Rechtsmanagement in der Ablauforganisation . . . . . . 15998

4. Kosten und Nutzen . . . . . . . . . . . . . . . . . . . . . . 16499

5. Zusammenfassung . . . . . . . . . . . . . . . . . . . . . . 169101

V. Planungsszenarien . . . . . . . . . . . . . . . . . . . 170102

VI. Vertragsvorbereitung . . . . . . . . . . . . . . . . . . . . . 174104

1. Planung . . . . . . . . . . . . . . . . . . . . . . . . 175104

2. Teamwork Interne Organisation, Computer und Software $180 \quad 106$

3. Ideensammlung . . . . . . . . . . . . . . . . . . . . . . . . 182107

4. Tatsachen und Meinungen . . . . . . . . . . . . . . . . . . $187 \quad 108$

5. Tatsachen und Bilder . . . . . . . . . . . . . . . . . . . 191109

6. Dokumentation . . . . . . . . . . . . . . . . . . . . . . 193110

7. Informationen über den Vertragspartner . . . . . . . . . 194110

8. Rechtslage . . . . . . . . . . . . . . . . . . . . . 195111 
9. Entwurfsregie ................. $200 \quad 113$

10. Interne Abstimmung der Entwürfe . . . . . . . . . . . $207 \quad 115$

11. Verträge mit ausländischen Vertragspartnern . . . . . . . 210115

12. Letter of Intent . . . . . . . . . . . . . . . . . . . . . . . . . $214 \quad 117$

\section{Vertragsdesign}

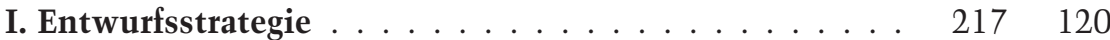

1. Vertragsformen . . . . . . . . . . . . . . . . . . $217 \quad 120$

2. Begriff: Vertragsdesign . . . . . . . . . . . . . . . $221 \quad 122$

3. Strategie und Taktik . . . . . . . . . . . . . . . . . . . . 229124

II. Wissensmanagement: Die Werkzeuge für das Vertragsdesign . . . . . . . . . . . . . . . . . . . . . 233126

1. Checklisten . . . . . . . . . . . . . . . . . . . 234127

2. Vertragsmuster . . . . . . . . . . . . . . . . . . . . . . . 237129

3. Vertragssammlungen . . . . . . . . . . . . . . . . . . . 238130

4. Rechtsprechung . . . . . . . . . . . . . . . . . . . . . 239130

5. Literatur . . . . . . . . . . . . . . . . . . . . . . . . . 240130

6. Datenbankinformationen und Newsletter . . . . . . 2412131

7. Softwareunterstützung . . . . . . . . . . . . . . . . . . . . $242 \quad 131$

8. Einbindung in das Firmennetzwerk . . . . . . . . . . $246 \quad 132$

9. Einbindung der Anwälte in das Netzwerk . . . . . . . . . $247 \quad 132$

10. Videokonferenzsysteme, Bildtelefonie (Skype) . . . . . . $248 \quad 132$

11. Hardwareausstattung . . . . . . . . . . . . . . . . . . . . . 249132

12. Elektronische Signaturen ．. . . . . . . . . . . . . $250 \quad 133$

III. Arbeitstechnik . . . . . . . . . . . . . . . . . . . . . . . . . $251 \quad 133$

1. Zettelsystem . . . . . . . . . . . . . . . . . . . . . . 253134

a) Grundidee: Ein Zettel = Ein Gedanke . . . . . . . . . 253134

b) Einheitliches Format . . . . . . . . . . . . . . . . . . 256136

2. Charts, Mind-Mapping . . . . . . . . . . . . . . . . . . 257136

3. Texte . . . . . . . . . . . . . . . . . . . . . . . 259137

4. Teamwork . . . . . . . . . . . . . . . . . . . 2612138

5. Zeitmanagement . . . . . . . . . . . . . . 262a 138

IV. Elemente des Vertragsdesigns . . . . . . . . . . . . . . . . 263138

1. Struktur von Verträgen . . . . . . . . . . . . . . . . . . . . 263138

2. Modulare Vertragssysteme . . . . . . . . . . . . . . . . $271 \quad 141$

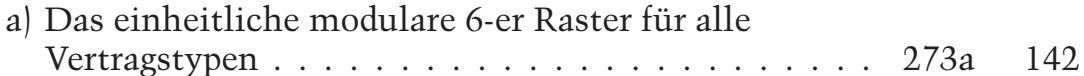


Rz. Seite

aa) Die sechs Module für Austauschverträge . . . . . 273b 142

bb) Die sechs Module für Gesellschaftsverträge . . . . $275 \quad 145$

b) Andere Aufteilung der Module . . . . . . . . . . . . . 276146

3. Sprache und Begriffe . . . . . . . . . . . . . . . . . . . . 279148

a) Umgangssprache . . . . . . . . . . . . . . . . . . . . . 2812149

b) Fachsprachen . . . . . . . . . . . . . . . . . . . 282149

c) Juristische Fachsprache . . . . . . . . . . . . . . . . . 283150

d) Fremdsprachliche Begriffe. . . . . . . . . . . . . . . . 284150

e) Sprachstile. . . . . . . . . . . . . . . . . . . 287151

aa) Neutraler Vertragsstil . . . . . . . . . . . . . . . 290152

bb) Konstruktiver Vertragsstil . . . . . . . . . . . . . . 2912153

cc) Destruktiver Vertragsstil . . . . . . . . . . . . . . 295154

dd) Gesichtsverlust . . . . . . . . . . . . . . . . . . 296155

ee) Stilistische Eleganz . . . . . . . . . . . . . . 297155

ff) Nur das Notwendige formulieren . . . . . . . . . 298155

f) Definitionen ............................. 156

V. Vertragsinhalt . . . . . . . . . . . . . . . . . . 300156

1. Umfang des Vertrages . . . . . . . . . . . . . . . . . . . 301157

2. Risikobeschreibung und Risikoverteilung . . . . . . . . . 302157

3. Entscheidungsfreiheit . . . . . . . . . . . . . . 305159

4. Systemverantwortung . . . . . . . . . . . . . . . . . 308160

5. Mitwirkungspflichten . . . . . . . . . . . . . . . . . 309161

6. Hauptleistungen und Nebenleistungen . . . . . . . . . . 310161

7. Regelung von Rechtsfolgen . . . . . . . . . . . . . . 311161

8. Gesetzliche Begriffe . . . . . . . . . . . . . . . . . 312162

9. Schließung von Lücken . . . . . . . . . . . . . . . . . . . . . . . . . . . . . . . 316

10. Inhaltliche Ausgewogenheit . . . . . . . . . . . . 315163

11. Schiedsgutachter . . . . . . . . . . . . 316163

VI. Ein System für die Entwicklung vertraglicher Regeln . . $318 \quad 164$

1. Der Gestaltungsraum der Verträge . . . . . . . . . . . . . 318164

2. Die Entwicklung gesetzlicher und vertraglicher Regeln . 319164

3. Bestimmende Faktoren für Verträge . . . . . . . . . . . . 320164

4. Probleme der gesetzlichen Lösung . . . . . . . . . . . . . 323165

a) Szenario: Leistungsstörungen bei Austauschverträgen 323165

aa) Die gesetzliche Lösung . . . . . . . . . . . . . . . . 324166

bb) Probleme der gesetzlichen Lösung . . . . . . . . . $325 \quad 367$

b) Szenario: Ausscheiden von Gesellschaftern . . . . . . 326167

5. Alternativen . . . . . . . . . . . . . . . . . 328169 
a) Leistungsstörungen bei Austauschverträgen . . . . . . $329 \quad 169$

aa) Veränderung des Leistungsinhalts . . . . . . . . . . 330169

bb) Kosten- und Risikovermeidung (Cheapest Cost Avoider) . . . . . . . . . . . . . . . . . . $331 \quad 170$

cc) Risikoübernahme durch Dritte (Cheapest Insurer) $332 \quad 170$

dd) Risikoübernahme durch den Überlegenen

(Superior Risk Bearer) . . . . . . . . . . . . . . . . . 333170

ee) Formale Vorgehensmodelle . . . . . . . . . . . . . . 334171

ff) Reduzierung des Streitrisikos . . . . . . . . . . . . . 335171

b) Ausscheiden von Gesellschaftern . . . . . . . . . . 337

6. Elemente, die die Risikoverteilung und Risikoakzeptanz beeinflussen. . . . . . . . . . . . . . . . . . . $343 \quad 177$

a) Ökonomische Analyse der vertraglichen Risikoverteilung . . . . . . . . . . . . . . . . . $343 \quad 177$

aa) Gesetzliche Zuweisung der Risiken . . . . . . . . . $345 \quad 178$

bb) Interpretation der Ermessensspielräume . . . . . . $346 \quad 178$

cc) Risikokategorien . . . . . . . . . . . . . . . . . . $347 \quad 178$

b) Analyse der ideellen Interessen und emotionalen Lagen der Parteien . . . . . . . . . . . . . . . . . . . . 348179

c) Macht, Information und Spiele . . . . . . . . . . . . . 349180

d) Das Problem der Gerechtigkeit . . . . . . . . . . . . . . $351 \quad 181$

e) Ergebnisorientierte, aber auch interessengerechte Verhandlungsführung . . . . . . . . . . . . . . . . $352 \quad 181$

f) Vorsorgliche Verminderung der Streitrisiken . . . . . . $353 \quad 181$

g) Komplexität . . . . . . . . . . . . . . . . . . . . . . . . . 355182

h) Check and Balance . . . . . . . . . . . . . . . . . . 356182

7. Naives Vorgehen bei der Entwicklung vertraglicher Regeln in der Praxis . . . . . . . . . . . . . . . . . . . 358

8. Systematisch richtiges Vorgehensmodell bei der Entwicklung von vertraglichen Rechtsregeln . . . . . . . . 360185

a) Macht, Logik, Analogiebildung und Stressfaktoren . . 360185

b) Erläuterung des Vorgehensmodells an einem Beispiel . 361b 186

aa) Phase 1: Definition des Risikoverteilungsmodells

(Regel) . . . . . . . . . . . . . . . . . $362 \quad 186$

bb) Phase 2: Ermittlung der Tatsachen (Fall) . . . . . . 363187

cc) Phase 3: Vergleich zwischen Risikoverteilung und Tatsachen (Analogie) . . . . . . . . . . . . . . . . . 364188

dd) Phase 4: Verhandlung und Entscheidung . . . . . . 365188

ee) Phase 5: Neue Alternativen. . . . . . . . . . . . . . 366189

ff) Zusammenfassung . . . . . . . . . . . . . . . . . . $367 \quad 189$ 


\section{Vertragsverhandlung}

I. Verhandlungsstrategie _. . . . . . . . . . . . . . . $368 \quad 192$

1. Die Verhandlung als soziales und kommunikatives Ritual . . . . . . . . . . . . . . . . . . 369192

2. Verhandlungsplanung. . . . . . . . . . . . . . 373193

II. Psychologische Faktoren bei Vertragsverhandlungen . . $378 \quad 195$

1. Positionen, Status und Machtspiele . . . . . . . . . . . 380196

2. Machtdifferenzen, Argumente und Gefühlslagen . . . $381 \quad 197$

a) Soziale und kommunikative Rituale . . . . . . . . . . 381a 198

b) Wirkung nach außen: Tatsachen sprechen lassen! . . 381b 199

c) Wirkung nach innen . . . . . . . . . . . . . . . . . . 381c 199

d) Argumente ändern Gefühle. . . . . . . . . . . . 381e 200

e) Funktion von Drohungen . . . . . . . . . . . . . 381f 200

3. Unbewusste Motive. . . . . . . . . . . . . . . . . . . . . . 382201

4. Flexibilität und Zuverlässigkeit . . . . . . . . . . . . . . 383201

5. Emotionale Lagen . . . . . . . . . . . . . . . . . . . . . 384202

a) Positive Emotionen . . . . . . . . . . . . 384a 202

b) Negative Emotionen und Stress . . . . . . . . . . 384b 203

6. Misstrauen und Vertrauen . . . . . . . . . . . . . . . . 385204

7. Respekt ................... 387a 204

III. Strategische Modelle . . . . . . . . . . . . . . . . . . . . . 388205

1. Tatsachen, Meinungen und Bewertungen . . . . . . . . . . 388205

2. Drei Basismodelle . . . . . . . . . . . . . . . . . . . . 389206

3. Basarhandel .................. 390a 206

4. Das Harvard-Verhandlungskonzept . . . . . . . . . . . . . 391207

5. Machiavelli in Harvard: Zwei gegensätzliche

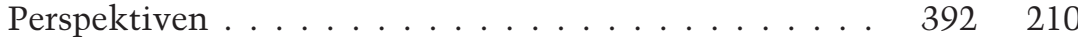

a) Die Entwicklung des Harvard-Verhandlungskonzepts $392 \mathrm{a} \quad 210$

b) Machiavellis Ideen . . . . . . . . . . . . . . . . . . . . 392c 211

c) Die Kombination der Perspektiven . . . . . . . . . 392f 213

aa) Unterschiedliche Machtperspektiven . . . . . 392f 213

bb) Situationsbedingte Werkzeuge. . . . . . . . . 392i 215

cc) Verbindung der Perspektiven . . . . . . . . . 3921216

6. Zusammenfassung ................. 392m 217

IV. Verhandlungsstil . . . . . . . . . . . . . . . . . . 395219

1. Neutrales Verhalten. . . . . . . . . . . . . . . . . 400222

2. Destruktives Verhalten . . . . . . . . . . . . . . 402222 
3. Konstruktives Verhalten . . . . . . . . . . . . . . . . . 405224

4. Bewertung der Stilformen . . . . . . . . . . . . . . . . 407224

5. Klarheit des Stils und Stilwechsel . . . . . . . . . . . . . 413228

6. Sprache, Verhalten und Körpersprache . . . . . . . . . . 415228

a) Aktives Zuhören . . . . . . . . . . . . . . . . . . . . . $418 \quad 230$

b) Unterbrechungen . . . . . . . . . . . . . . . . . . . . . . 419230

c) Endlose Reden . . . . . . . . . . . . . . . . . . . . . . . 420230

d) Ich- und Du-Botschaften . . . . . . . . . . . . . . . 420a 231

7. Direkte und indirekte Kommunikation . . . . . . . . 421232

a) Indirektes Verhalten . . . . . . . . . . . . . . . . . . . 423233

b) Direktes Verhalten . . . . . . . . . . . . . . . . . . . . 424233

V. Logische, komplexe und emotionale Intelligenz . . . . $426 \quad 234$

1. Logische Gedankenführung . . . . . . . . . . . . . 426a 234

2. Emotionale Lagen . . . . . . . . . . . . . . . . 426b 235

3. Komplexe Situationen . . . . . . . . . . . . . . . 426c 235

VI. Sieben Konfliktelemente . . . . . . . . . . . . . . . . . . 427236

VII. Verhandlungsorganisation . . . . . . . . . . . . . . . . . $432 \quad 238$

1. Ad-hoc-Verträge . . . . . . . . . . . . . . . . . . . . . 432238

2. Beweis des Vertragsschlusses . . . . . . . . . . . . . 434238

3. Komplexe Verträge. . . . . . . . . . . . . . . . . . . . . . 435239

4. Verträge ohne Verhandlungskonferenzen . . . . . . 436240

5. Verträge als Ergebnis von Verhandlungskonferenzen . . 438240

a) Vorverhandlung . . . . . . . . . . . . . . . . . . . . . . 439241

b) Entwurfsverhandlung . . . . . . . . . . . . . . . . . . . 440241

c) Schlussverhandlung . . . . . . . . . . . . . . . . . 4 $442 \quad 242$

6. Organisation von Verhandlungen . . . . . . . . . . . . . 446243

a) Taktische Überlegungen . . . . . . . . . . . . . . . . . . 446243

b) Verhandlungsregie . . . . . . . . . . . . . . . . . . . . . . 449245

c) Themen . . . . . . . . . . . . . . . . . . . . . . 453246

d) Tagesordnung . . . . . . . . . . . . . . . . . . . . . . . 4455247

e) Teilnehmer . . . . . . . . . . . . . . . . . . . . . 456247

aa) Verhandlungen unter vier Augen . . . . . . . . 456247

bb) Verhandlungsteams . . . . . . . . . . . . . . . . . 456a 248

cc) Rollenspiele. . . . . . . . . . . . . . . . . . . . 460250

dd) Spannungen im Team . . . . . . . . . . . . . . . . 461250

ee) Aus der Rolle fallen . . . . . . . . . . . . . . . . $462 \quad 251$

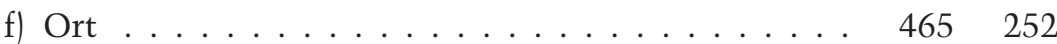


g) Zeit . . . . . . . . . . . . . . . . . . . . . . . . . . . $468 \quad 254$

aa) Zeitplanung. . . . . . . . . . . . . . . 468254

bb) Taktik . . . . . . . . . . . . . . . . . . 469254

cc) Pausen.................... 471255

dd) Zwischenergebnisse. . . . . . . . . . . . $472 \quad 255$

ee) Fehlende Strukturierung . . . . . . . . . . . . 473255

h) Arbeitstechnik mit Zetteln und Software . . . . . . $474 \quad 256$

i) Organisatorische Details . . . . . . . . . . . . . . 476257

aa) Sitzordnung. . . . . . . . . . . . . . . 477257

bb) Unterlagen vorbereiten . . . . . . . . . . . . . 478258

cc) Visitenkarten . . . . . . . . . . . . . . . . . . 479258

dd) Visuelle Hilfsmittel . . . . . . . . . . . . . . . . 480259

ee) Protokolle... . . . . . . . . . . . . . 481259

ff) Dokumente und Anlagen . . . . . . . . . . . . $482 \quad 260$

gg) Getränke .................. . 483260

hh) Rauchen. . . . . . . . . . . . . . . . . . . . 484260

ii) Essen. . . . . . . . . . . . . . . . . . . 485260

ij) Alkohol ................... 486261

kk) Dokumentenmanagement . . . . . . . . . . 487262

11) Aktenkoffer. . . . . . . . . . . . . . . . . . . . $488 \quad 262$

mm) Mobiltelefone . . . . . . . . . . . . . . . . . 489262

nn) Computer und Software . . . . . . . . . . . . 490263

oo) Taschenrechner . . . . . . . . . . . . . . 491263

pp) Telefax, E-Mail . . . . . . . . . . . . . . . . . . . 492263

qq) Sekretariatsdienste . . . . . . . . . . . . . 493263

rr) Ausweichräume . . . . . . . . . . . . . . . . . . . 494264

ss) Entertainment . . . . . . . . . . . . . . 495265

tt) Schlaf ................... 496265

uu) Sprachprobleme . . . . . . . . . . . . $497 \quad 265$

vv) Übersicht behalten . . . . . . . . . . . . . . . . 499267

VIII. Verhandlungsregie . . . . . . . . . . . . . . . . . . . . . 500267

1. Allgemeines . . . . . . . . . . . . . . . . . . . . . 500267

2. Werkzeuge der Verhandlungsregie . . . . . . . . . . . . . 502268

a) Übersicht . . . . . . . . . . . . . . . . . . . . . . . . $502 \quad 268$

b) Grundregeln . . . . . . . . . . . . . . . . . . . . . . 503269

3. Übernahme der Verhandlungsregie . . . . . . . . . . . $504 \quad 270$

4. Tatsachenorientiertes Verhalten. . . . . . . . . . . . 507271

5. Verhandlungsteams . . . . . . . . . . . . . . . . . . . 508272

6. Einsatz der Werkzeuge . . . . . . . . . . . . . . . . . 510273 
a) Ergebnisse zusammenfassen . . . . . . . . . . . . . . . 511273

b) Wiederholen. . . . . . . . . . . . . . . . . . . . . . . . 512274

c) Regeln brechen . . . . . . . . . . . . . . . . . . . . . 513274

d) Strukturen schaffen . . . . . . . . . . . . . . . . . . . $515 \quad 275$

aa) Informieren . . . . . . . . . . . . . . . . 516275

bb) Strukturieren . . . . . . . . . . . . . . . . . . . $517 \quad 276$

cc) Detaillieren. . . . . . . . . . . . . . . . . . . 518276

dd) Dokumentieren . . . . . . . . . . . . . . . . . . . 519277

ee) Bewerten . . . . . . . . . . . . . . . . . . . . 520278

ff) Entscheiden . . . . . . . . . . . . . 521278

e) Zwölf taktische Regeln . . . . . . . . . . . . . . . . 521a 278

IX. Verhandlungsablauf . . . . . . . . . . . . . . . . . . . . 522280

1. Anfangsphase . . . . . . . . . . . . . . . . . . . . 524280

2. Vereinbarung über Protokolle . . . . . . . . . . . . . 528283

3. Verhandlung über den Vertragsinhalt . . . . . . . . . . . 529283

a) Statements . . . . . . . . . . . . . . . . . . . . . . . 529283

b) Verhandlungsstil . . . . . . . . . . . . . . . . . . . . . 533285

c) Störfelder . . . . . . . . . . . . . . . . . . . . . . 534285

d) Forderungen stellen . . . . . . . . . . . . . . . . . . 535286

e) Reaktion auf Forderungen. . . . . . . . . . . . . . . 536286

f) Abwarten und Schweigen . . . . . . . . . . . . . . . . 537287

g) Abkürzen endloser Reden . . . . . . . . . . . . . . . 537a 287

4. Bewertung der eigenen Position . . . . . . . . . . . . . 538287

a) Zwischenbilanz. . . . . . . . . . . . . . . . . . . $538 \quad 287$

b) Vorzeitiger Abbruch . . . . . . . . . . . . . . . . . . . 540b 289

5. Lösungen suchen: Die Bilanz der Zugeständnisse . . . . 541290

a) Kultureller und sozialer Hintergrund . . . . . . . . . $542 \quad 290$

b) Komplexes Denken . . . . . . . . . . . . . . . . . . . 543291

c) Verhandlungsstil . . . . . . . . . . . . . . . . . . . . . . 547293

aa) Lob des Konjunktivs . . . . . . . . . . . . . . 548293

bb) Fragen und Schweigen . . . . . . . . . . . . . . . 549294

cc) Scheinzugeständnisse . . . . . . . . . . . . . . . 550294

d) Gegenüberstellung von Leistung und Gegenleistung . $\quad 551295$

e) Objektive Risikobewertung . . . . . . . . . . . . . . . . 556297

f) Emotionale Bewertung . . . . . . . . . . . . . . . . . 557297

g) Rechtliche Bewertung . . . . . . . . . . . . . . . . . 559298

h) Vorteile für beide Seiten suchen . . . . . . . . . . . . . 560299

i) Alternativen entwickeln und anschaulich machen . . $562 \quad 300$ 
j) Entscheidungskompetenzen . . . . . . . . . . . . $565 \quad 301$

k) Letzte Forderungen . . . . . . . . . . . . . . . . . . $566 \quad 302$

6. Ergebnislosigkeit des ergebnisorientierten Verhandelns 567a 302

7. Organisation des Abbruchs von Verhandlungen . . . 5 567b 303

X. Schwierige Verhandlungssituationen . . . . . . . . . . . $568 \quad 304$

1. Allgemeine Verhaltenshinweise . . . . . . . . . . . . . 569305

a) Vier-Stufen-Plan bei offenen Krisen . . . . . . . . . 571306

b) Strategien der Leere . . . . . . . . . . . . . . . . $575 \quad 308$

c) Unsinnige Forderungen . . . . . . . . . . . . . . . . . $578 \quad 309$

d) Auflösen von Pattsituationen . . . . . . . . . . . . . 579309

e) Ultimative Forderungen . . . . . . . . . . . . . . . . 581310

f) Übersicht über die Fallgruppen . . . . . . . . . . . . . . . . . . . 582 311

2. Neutrale Probleme. . . . . . . . . . . . . . . . . $583 \quad 312$

3. Beeinflussung des Verhandlungsablaufs . . . . . . . . . . $586 \quad 313$

4. Taktieren . . . . . . . . . . . . . . . . . . 591315

a) Zu hohe Forderungen . . . . . . . . . . . . . . . . . $592 \quad 316$

b) Zu geringe Forderungen . . . . . . . . . . . . . . . 593316

c) Zurücknehmen von Zugeständnissen . . . . . . . . . $595 \quad 317$

d) Inhaltsleere Zusagen . . . . . . . . . . . . . . . . . . . 596317

e) Unbegründete Zweifel . . . . . . . . . . . . . . . . . $597 \quad 318$

5. Manipulation von Tatsachen . . . . . . . . . . . . . . . . 598318

6. Manipulation von Meinungen . . . . . . . . . . . . . . . $602 \quad 319$

7. Destruktion und Machtspiele . . . . . . . . . . . . $605 \quad 320$

a) Offene Konfrontation . . . . . . . . . . . . . . . 609322

b) Prinzipienreiterei . . . . . . . . . . . . . . . . . . . . . $610 \quad 322$

c) Skepsis . . . . . . . . . . . . . . . . . . . . . . . . . . . . . 6 . . . . . . . . . . . . 613

d) Drohungen . . . . . . . . . . . . . . . . . . . . . . . . . $613 \quad 323$

e) Unhöflichkeiten . . . . . . . . . . . . . . . . . . . 614324

8. Interne Konfliktsituationen . . . . . . . . . . . . $615 \quad 325$

a) Denkverbote und Killerphrasen . . . . . . . . . . . . . $616 \quad 325$

b) Änderungen von Anweisungen . . . . . . . . . . . . . $618 \quad 326$

c) Gefühlsschwankungen . . . . . . . . . . . . . . . . 619327

XI. Abbruch der Verhandlungen . . . . . . . . . . . . . . $622 \quad 328$

XII. Formeller Vertragsschluss _ . . . . . . . . . . . . . . . $629 \quad 330$

XIII. Checkliste: Von der Idee zum Text - Ein

Vorgehensmodell . . . . . . . . . . . . . . 634a 333 


\section{Vertragsdurchführung}

I. Planung der Durchführung . . . . . . . . . . . . . . . 635337

II. Planungsfaktoren und eigene Vertragstreue . . . . . . 639339

III. Strategie und Taktik . . . . . . . . . . . . . . . . . . . . 641340

IV. Durchführungsregie . . . . . . . . . . . . . . . . . . . 645342

V. Projektteams bei der Durchführung _. . . . . . . . . 647343

VI. Wirksamkeit des Vertrages . . . . . . . . . . . . . . . . 649344

VII. Sicherung der Leistungen . . . . . . . . . . . . . . . . 651344

VIII. Treuhandabwicklungen . . . . . . . . . . . . . . . . . $652 \quad 345$

IX. Geld- und Sachleistungen ～. . . . . . . . . . . . . . . 653345

X. Leistungsänderungen und Planänderungen . . . . . . 656346

XI. Rechtshandlungen im Bereich der Vertragsdurchführung . . . . . . . . . . . . . . . . . . . . . . . 660 348

XII. Der Vertrag in der Krise . . . . . . . . . . . . . . . . . . 661349

1. Strategie und Taktik . . . . . . . . . . . . . . . . . . . . . 661349

2. Auslöser für die Krise . . . . . . . . . . . . . . . . . . . . $664 \quad 350$

3. Verhinderung von Vertragskrisen . . . . . . . . . . . . . 665354

a) Allgemeines Verhalten . . . . . . . . . . . . . . . . . . 665354

b) Streitrisikoanalysen . . . . . . . . . . . . . . . . . 666a 355

4. Umgang mit der Presse . . . . . . . . . . . . . . . . . . $668 \quad 356$

5. Rechtliche Bewertung . . . . . . . . . . . . . . . . . . . 669356

6. Unterstützung durch Berater in der Krise . . . . . . . 671358

7. Krisensitzungen . . . . . . . . . . . . . . . . . . . . . . $673 \quad 359$

8. Rückabwicklung des Vertrages . . . . . . . . . . . $682 \quad 362$

\section{Vertragscontrolling}

I. Begriff . . . . . . . . . . . . . . . . . . . . . . . . . . . . . $686 \quad 365$

II. Werkzeuge ． . . . . . . . . . . . . . . . . . . . . . . . 687365

III. Bandbreite des Vertragscontrollings ．. . . . . . . . . 690367

IV. Vertragsdokumentation . . . . . . . . . . . . . . . . 691367

V. Nachkalkulation . . . . . . . . . . . . . . . . . . . . . . . 694368

VI. Gemeinsames Controlling von Ergebnissen . . . . . . . 695369 


\section{Teil 3 \\ Austauschverträge \\ (Imbeck) \\ Rz. Seite \\ 1 Einführung \\ $1 \quad 371$ \\ 2 Vertragsanbahnung}

I. Rechtliche Qualifikation von Vorbereitungsmaßnahmen . . . . . . . . . . . . . . . . . . . . . . . 14377

1. Letter of Intent/Absichtserklärung . . . . . . . . . . . . 14377

a) Begriff . . . . . . . . . . . . . . . . . . . . . . . . $14 \quad 377$

b) Zweck . . . . . . . . . . . . . . . . . . . . . . . . . . . . 15377

c) Form . . . . . . . . . . . . . . . . . . . . . . . $16 \quad 378$

d) Rechtliche Bedeutung . . . . . . . . . . . . . . . . . . $17 \quad 378$

e) Rechtsfolgen des Fehlens eines Letter of Intent . . . . $18 \quad 378$

f) Literatur . . . . . . . . . . . . . . . . . . . . . . . 20378

2. Memorandum of Understanding . . . . . . . . . . . $21 \quad 379$

3. Third Party Legal Opinion . . . . . . . . . . . . . . . . $23 \quad 379$

a) Begriff . . . . . . . . . . . . . . . . . . . $23 \quad 379$

b) Rechtliche Bedeutung und Rechtsfolgen . . . . . . . . $25 \quad 380$

c) Literatur . . . . . . . . . . . . . . . . . . . . . . . $26 \quad 380$

4. Isolierte Geheimhaltungsvereinbarung _ . . . . . . . . $27 \quad 2780$

5. Vorvertrag und Option . . . . . . . . . . . . . . . . $28 \quad 381$

6. Vertrauensschadenshaftung . . . . . . . . . . . . 33382

7. Handelndenhaftung . . . . . . . . . . . . . . . . . 35383

II. Aufklärungs- und Schutzpflichten . . . . . . . . . . . . $36 \quad 383$

1. Aufklärungspflichten . . . . . . . . . . . . . . . . $37 \quad 383$

a) Grundsätze . . . . . . . . . . . . . . . . . . . . . . $37 \quad 383$

b) Folgen . . . . . . . . . . . . . . . . . . . . . . . . . . $38 \quad 384$

c) Beispiele . . . . . . . . . . . . . . . . . . . . . . . . . . . 39384

2. Schutzpflichten . . . . . . . . . . . . . . . . $40 \quad 385$

III. Verpflichtung zur Vertraulichkeit . . . . . . . . . . . 41385

1. Zivilrechtlicher Schutz . . . . . . . . . . . . . . . . . $42 \quad 386$

2. Strafrechtlicher Schutz . . . . . . . . . . . . . . $47 \quad 387$

IV. Verschulden bei Vertragsverhandlungen . . . . . . . . 49387

1. Vertrauenshaftung. . . . . . . . . . . . . . . . . . 50388

2. Erfüllungsgehilfen . . . . . . . . . . . . . . . . . $53 \quad 389$

3. Eigenhaftung des Vertreters . . . . . . . . . . . . . . . 54389

4. Beweislast . . . . . . . . . . . . . . . . $56 \quad 390$ 
V. Allgemeine Geschäftsbedingungen/Formularverträge . $\quad \begin{array}{lll}57 & 391\end{array}$

1. Begriff . . . . . . . . . . . . . . . . . . $58 \quad 391$

2. Sachlicher und persönlicher Geltungsbereich . . . . . $59 \quad 392$

a) Sachlicher Anwendungsbereich . . . . . . . . . . 59392

b) Persönlicher Anwendungsbereich . . . . . . . . . . $60 \quad 392$

3. Einbeziehung . . . . . . . . . . . . . . . . . . . . 61393

4. Zulässigkeit der Klauseln . . . . . . . . . . . . . . . . . . $62 \quad 62393$

5. Verbraucherverträge . . . . . . . . . . . . . . . $63 \quad 394$

VI. Vollmachten . . . . . . . . . . . . . . . . . . . . . . $66 \quad 395$

1. Verhandlungsvollmacht . . . . . . . . . . . . . $67 \quad 395$

2. Abschlussvollmacht . . . . . . . . . . . . . . . . 69396

3. Duldungs- und Anscheinsvollmacht . . . . . . . . . $\quad 71397$

a) Duldungsvollmacht . . . . . . . . . . . . . . . . . $72 \quad 397$

b) Anscheinsvollmacht . . . . . . . . . . . . . . . $73 \quad 397$

4. Vollmachtloser Vertreter . . . . . . . . . . . . . . . . 74398

VII. Konsens und Dissens . . . . . . . . . . . . . . . . . . . 76398

1. Offener Einigungsmangel . . . . . . . . . . . . . . . . . $77 \quad 399$

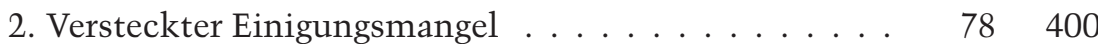

VIII. Scheinvertrag . . . . . . . . . . . . . . . . . . . . . . 79400

IX. Anfechtbarkeit . . . . . . . . . . . . . . . . . $81 \quad 401$

1. Irrtum . . . . . . . . . . . . . . . . . . . . . . 8284

2. Täuschung und Drohung . . . . . . . . . . . . . 85402

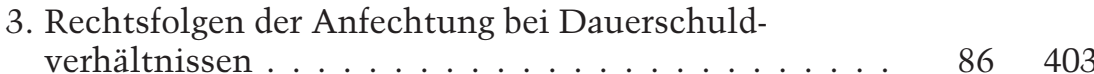

4. Vermögensverschiebungen . . . . . . . . . . . . . . . 89404

X. Geschäftsgrundlage . . . . . . . . . . . . . . . . . . $90 \quad 404$

XI. Sittenwidrigkeit . . . . . . . . . . . . . . . . . . . . 94906

1. Allgemeines . . . . . . . . . . . . . . . . . . 95954

2. Wucher . . . . . . . . . . . . . . . . . . . . . 99408

XII. Gesetzliche Verbote . . . . . . . . . . . . . . . . . . . . . 100409

\section{Vertragsinhalt}

I. Vorfragen . . . . . . . . . . . . . . . . . . . . . . . . . 1014

1. Formerfordernisse . . . . . . . . . . . . . . . . 102412

a) Gesetzliche Formerfordernisse . . . . . . . . . . . . 105414

aa) Vertragstypus und Vertragszweck . . . . . . . . 106414 
bb) Einzelne Vertragsbestandteile . . . . . . . . . . . . $108 \quad 415$

(1) Schuldbestärkung und -sicherung . . . . . . . . $109 \quad 415$

(2) Dinglicher Vollzug . . . . . . . . . . . . . . . . $110 \quad 415$

(3) Sonstige Vertragsbestandteile . . . . . . . . . . 111416

cc) Zustimmungs- oder Ermächtigungshandlungen . . $112 \quad 416$

b) Formbedürftigkeit von Vorverträgen . . . . . . . . . . . $114 \quad 417$

c) Umfang der Formbedürftigkeit . . . . . . . . . . . . . . $117 \quad 418$

d) Probleme der Schriftform . . . . . . . . . . . . . . . . . 119419

aa) Einheitlichkeit der Urkunde . . . . . . . . . . . . . 119419

bb) Schriftform und Telekommunikation . . . . . . . . $122 \quad 420$

cc) Unterzeichnung . . . . . . . . . . . . . . . . . . . 123421

e) Besondere prozedurale Pflichten . . . . . . . . . . . . . $124 \quad 422$

aa) Trennung von Urkunden . . . . . . . . . . . . . . . $124 \quad 422$

bb) Hinweis- und Belehrungspflichten. . . . . . . . . . 125422

2. Vertragssprache . . . . . . . . . . . . . . . . . . . $126 \quad 422$

3. Übertragung von Rechten und Pflichten . . . . . . . . . . 129423

a) Drittbegünstigung . . . . . . . . . . . . . . . . . . . . . 129423

b) Schutzpflichten zugunsten Dritter . . . . . . . . . . . . $131 \quad 424$

c) Abtretung von Ansprüchen aus dem Vertrag . . . . . . $138 \quad 427$

d) Antizipierter Vertragsübergang . . . . . . . . . . . . . . $142 \quad 428$

4. Vertragspartner . . . . . . . . . . . . . . . . . . . . . 143429

a) Vertretung . . . . . . . . . . . . . . . . . . . . . . . 143429

aa) Dokumentation der Vertretungsmacht . . . . . . . 143429

bb) Vertreter ohne Vertretungsmacht . . . . . . . . . . $144 \quad 430$

cc) Einräumung von Vertretungsmacht zwischen den Vertragsparteien . . . . . . . . . . . . . . . . . 145431

dd) Vollmacht an Dritte . . . . . . . . . . . . . . . . . . $146 \quad 431$

ee) Vertretung Minderjähriger . . . . . . . . . . . . . 147431

b) Zugangsvereinbarungen . . . . . . . . . . . . . . . . . . . . $148 \quad 431$

aa) Empfangsvollmacht . . . . . . . . . . . . . . . . . . 149432

bb) Modifikation allgemeiner Zugehensregelungen . . $\quad 150 \quad 432$

c) Mehrheit von Vertragspartnern . . . . . . . . . . . . . 152433

d) Änderung in der Person des Vertragspartners . . . . . . $154 \quad 434$

aa) Änderungen im Gesellschafterbestand bei

Gesellschaften . . . . . . . . . . . . . . . . 155434

bb) Rechtsformwechsel . . . . . . . . . . . . . . . . . $157 \quad 435$

cc) Verschmelzung oder Spaltung des Vertragspartners $158 \quad 436$

dd) Insolvenz des Vertragspartners . . . . . . . . . . . . 160436

ee) Tod des Vertragspartners . . . . . . . . . . . . . . 162437 
e) Geschäftsfähigkeit der Vertragspartner . . . . . . . . . 163438

5. Verhältnis zu anderen Verträgen . . . . . . . . . . . . . . . 164438

a) Formaspekt . . . . . . . . . . . . . . . . . . . . . . . 165438

b) Einwendungsdurchgriff . . . . . . . . . . . . . . . . 166438

c) Koordination/Systemverantwortung . . . . . . . . . . $168 \quad 439$

6. Einfluss Dritter auf den Vertrag . . . . . . . . . . . . . . 170440

a) Öffentlich-rechtliche Beschränkungen . . . . . . . . . 171441

aa) Einfluss auf die Wirksamkeit . . . . . . . . . . . . 171441

bb) Einfluss auf die Erreichung des Vertragszwecks . . $175 \quad 442$

b) Privatrechtliche Beschränkungen . . . . . . . . . . $176 \quad 443$

aa) Schlicht schuldrechtliche Beschränkungen . . . . 176443

bb) Beeinflussung der Wirksamkeit des Vertrages . . . $177 \quad 443$

cc) Einfluss Dritter auf die Durchführung des Vertrages $178 \quad 444$

c) Vorkaufsrechte . . . . . . . . . . . . . . . . . . . . . . . 179444

7. Haftungsrisiken aus dem Leistungsaustausch . . . . . . . 181445

a) Vermögensübernahme (§ 419 BGB a.F.) . . . . . . . . . 182445

b) Haftung aus Firmenfortführung (§25 HGB) . . . . . . . 183446

c) Haftung des Betriebsübernehmers (§ 613a BGB) . . . . 185447

d) Steuerliche Risiken . . . . . . . . . . . . . . . . . . . . 187447

e) Haftungsrisiko beim Erwerb von Gesellschaftsanteilen 189448 aa) Kapitalgesellschaften . . . . . . . . . . . . . . . . . 189448

bb) Personengesellschaften . . . . . . . . . . . . . . . . 190449

f) Öffentlich-rechtliche Haftung . . . . . . . . . . . . 191449

8. Externe Effekte des Vertragsinhalts . . . . . . . . . . . 192450

a) Gesetzes- und Vertragsumgehung . . . . . . . . . . . . 193450

b) Steuerrechtliche Folgen . . . . . . . . . . . . . . . . 1954451

aa) Berücksichtigung von Steuerfolgen . . . . . . . . 196451

bb) Planung von Steuerfolgen . . . . . . . . . . . . . . . 197451

II. Vertragliche Grundlagen ... . . . . . . . . . . . . . . 1984452

1. Vertragsrubrum . . . . . . . . . . . . . . . . . . . . . 1994452

2. Präambel oder Vorbemerkung . . . . . . . . . . . . . . 201453

a) Erläuterungsfunktion. . . . . . . . . . . . . . . . . . . 202453

b) Dokumentationsfunktion . . . . . . . . . . . . . . . . 2034454

c) Struktur der Präambel oder Vorbemerkung . . . . . . . $204 \quad 454$

3. Registerstand . . . . . . . . . . . . . . . . . . . . . 205454

4. Begriffsdefinitionen . . . . . . . . . . . . . . 206455

5. Geltungsbereich des Vertrages . . . . . . . . . . . . . 207456

a) Sachlicher Geltungsbereich . . . . . . . . . . . . . . $207 \quad 456$

b) Räumlicher Geltungsbereich . . . . . . . . . . . . . . . 208456 
6. Rangfolge von Regelungen . . . . . . . . . . . . . . . . 209456

a) Verhältnis zwischen Vertrag und Gesetz . . . . . . . . 209456

aa) Zwingendes Gesetzesrecht . . . . . . . . . . . . . 210456

bb) Dispositives Recht der Vertragstypen . . . . . . . . $213 \quad 457$

b) Einbeziehung von Regelungssystemen außerhalb des Vertragstextes . . . . . . . . . . . . . . . . . . 215458 aa) Regelungsprogramme von Dritten . . . . . . . . 215458

bb) Allgemeine Geschäftsbedingungen . . . . . . . . . $217 \quad 459$

c) Interne Rangfolge . . . . . . . . . . . . . . . . . . . 223461

III. Inhalt der Leistungen . . . . . . . . . . . . . . . . . . . $224 \quad 461$

1. Sachleistung . . . . . . . . . . . . . . . . . . 225462

a) Leistungsart . . . . . . . . . . . . . . . . . . . . . . . . . . . . . . . . . . . . . . . . . 462

aa) Allgemeines . . . . . . . . . . . . . . 225462

bb) Beschaffenheitsvereinbarungen/Zusicherungen/

Garantien . . . . . . . . . . . . . . . . . . . . 228463

cc) Leistungsinhalt bei Typenmischung . . . . . . . . 233465

b) Leistungsmodalitäten . . . . . . . . . . . . . . . . . . . 235 465

c) Leistungsvorbehalte . . . . . . . . . . . . . . . . . . . . 236466

d) Mitwirkung des Vertragspartners . . . . . . . . . . . $240 \quad 467$

e) Leistungen Dritter . . . . . . . . . . . . . . . . . . . . 241468

f) Leistungszeit . . . . . . . . . . . . . . . . . . . . . . 242468

2. Geldleistung . . . . . . . . . . . . . . . . . . . . . 243469

a) Vergütung . . . . . . . . . . . . . . . . . . . . . . 243469

aa) Abbedingung gesetzlicher Regelungen . . . . . . . $244 \quad 469$

bb) Festpreis. . . . . . . . . . . . . . . . . . . . . . . . $245 \quad 469$

cc) Preisrahmen . . . . . . . . . . . . . . . . . . . 246469

dd) Vergütung nach Aufwand . . . . . . . . . . . . . . $248 \quad 470$

ee) Preisgleitklauseln . . . . . . . . . . . . . . . . . . . 249470

ff) Preisverrentung . . . . . . . . . . . . . . . 250470

gg) Abhängigkeit der Geldleistung vom Umsatz, Gewinn etc. . . . . . . . . . . . . . . . . . 252471

hh) Wertsicherungsklauseln . . . . . . . . . . . . . 255472

ii) Umsatzsteuer . . . . . . . . . . . . . . . . . . . . 2 256473

b) Zahlungsmodalitäten . . . . . . . . . . . . . . . . . . $257 \quad 473$

aa) Fälligkeitsregelungen . . . . . . . . . . . . . . . 257473

bb) Rechtsfolgen bei Abschlagszahlungen und

cc) Boni/Skonti/Rabatte . . . . . . . . . . . . . . . . . 259473 
dd) Aufrechnung . . . . . . . . . . . . . . . . . . . . . 260474

ee) Zurückbehaltungs-/Leistungsverweigerungsrechte $261 \quad 474$

3. Leistungsbestimmungsrechte . . . . . . . . . . . . . . 262474

4. Regelung des Verzuges . . . . . . . . . . . . . . . . . . . 264475

IV. Sicherung der Leistungen $\ldots \ldots$. . . . . . . . . . . . . . 269476

1. Sicherung der Sachleistung . . . . . . . . . . . . . . . . 269476

a) Gewährleistung. . . . . . . . . . . . . . . . . . . . . . 269476

b) Garantien . . . . . . . . . . . . . . . . . . . . . . . . . . 270477

c) Rügepflichten, Fristen . . . . . . . . . . . . . . . . . . 271477

d) Qualitätssicherungsvereinbarungen . . . . . . . . . . $273 \quad 478$

e) Bürgschaften . . . . . . . . . . . . . . . . . . . . . . $274 \quad 478$

f) Anwartschaftsrechte, Vormerkung . . . . . . . . $275 \quad 479$

2. Sicherung der Geldleistung . . . . . . . . . . . . . . . . 276479

a) Wahl des Zahlungsweges . . . . . . . . . . . . . . $276 \quad 479$

b) Eigentumsvorbehalt . . . . . . . . . . . . . . . . . . . $277 \quad 479$

c) Typische Kreditsicherheiten . . . . . . . . . . . . . $278 \quad 480$

aa) Sicherungsmittel . . . . . . . . . . . . . . . . . . 279481

(1) Sicherungsübereignung . . . . . . . . . . . . . $279 \quad 481$

(2) Sicherungszession . . . . . . . . . . . . . . . . 280481

(3) Grundpfandrechte . . . . . . . . . . . . . . . $281 \quad 481$

bb) Sicherungsabreden . . . . . . . . . . . . . . . . . . . 282482

d) Sicherung des Zahlungsflusses . . . . . . . . . . . . . . $287 \quad 484$

e) Drittsicherheiten . . . . . . . . . . . . . . . . . . . . . . 288484

aa) Bürgschaft . . . . . . . . . . . . . . . . . . 289484

bb) Schuldbeitritt . . . . . . . . . . . . . . . . . . . 290485

cc) Garantie. . . . . . . . . . . . . . . . . . . . . . 291485

3. Allgemeine Leistungssicherung . . . . . . . . . . . . . . 292486

a) Versicherungen . . . . . . . . . . . . . . . . . . . . . 293486

b) Informationsrechte und -pflichten . . . . . . . . . . . 294486

c) Konkurrenz- und Geheimnisschutz . . . . . . . . . . 295487

4. Allgemeine Haftungsvereinbarungen . . . . . . . . . 297487

a) Regelung einer Haftung wegen Pflichtverletzung im vorvertraglichen Bereich . . . . . . . . . . . . . . . . 298488

b) Verschuldensregelungen . . . . . . . . . . . . . . . . 299488

c) Haftungsausschlüsse und Haftungsbegrenzungen . . . $300 \quad 488$

d) Regelung der Haftungsfolgen . . . . . . . . . . . . . . . 301489

e) Verjährungsregelungen . . . . . . . . . . . . . . . . . . $304 \quad 490$

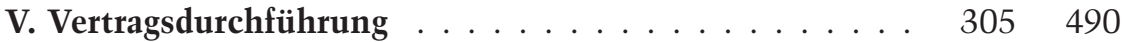


1. Leistungsvollzug . . . . . . . . . . . . . . . . . . . . . . . 305490

2. Beginn und Beendigung des Vertrages _. . . . . . . . 306490

a) Beginn des Vertrages . . . . . . . . . . . . . . . . . . . 306490

b) Laufzeit . . . . . . . . . . . . . . . . . . . . . . . . . . 307490

c) Vertragsbeendigung. . . . . . . . . . . . . . . . . . . . 308491

aa) Ordentliche Kündigung . . . . . . . . . . . . . . . 309491

bb) Außerordentliche Kündigung . . . . . . . . . . 310491

cc) Rücktrittsrechte . . . . . . . . . . . . . . . . . . 312492

3. Vertragsanpassung/Vertragsänderung . . . . . . . . . . $313 \quad 492$

4. Abnahme und Übergabe . . . . . . . . . . . . . . . . . . 316493

5. Besondere Nebenpflichten . . . . . . . . . . . . . . 317493

6. Abwicklungs- und nachvertragliche Pflichten . . . . . 318493

a) Abfindungen bei Vertragsbeendigung . . . . . . . . . 318493

b) Herausgabepflichten . . . . . . . . . . . . . . . . . . . 319494

c) Unterlassungs- und sonstige Pflichten . . . . . . . $320 \quad 494$

VI. Allgemeine Bestimmungen … . . . . . . . . . . . . . 321494

1. Rechtswahl . . . . . . . . . . . . . . . . . . . . . . 321494

2. Erfüllungsort und Gerichtsstand . . . . . . . . . . . 323495

a) Vereinbarung des Erfüllungsortes . . . . . . . . . . . 323495

b) Gerichtsstandsvereinbarungen . . . . . . . . . . . . $324 \quad 495$

3. Schriftformklauseln . . . . . . . . . . . . . . . . . . . . 325496

4. Salvatorische Klauseln . . . . . . . . . . . . . . . . . . 326497

5. Schiedsregelungen . . . . . . . . . . . . . . . . . . . . . . 328498

a) Schiedsgutachten . . . . . . . . . . . . . . . . . . $328 \quad 498$

b) Schiedsgerichtsvereinbarungen . . . . . . . . . . . . . 329498

6. Kosten/Steuern . . . . . . . . . . . . . . . . . . . . . . . . 331499

VII. Anlagen . . . . . . . . . . . . . . . . . . . . . . . . . . . . 332499

\section{Vertragsdurchführung}

I. Auslegung/Lückenfülllung . . . . . . . . . . . . . . 334501

II. Anfechtung/Kündigung/Rücktritt . . . . . . . . . . . . 335501

III. Vertrauensschutz bei Rückabwicklung . . . . . . . . . . 338502

IV. Bereicherungsrechtliche Fragen . . . . . . . . . . . . 339502

V. Vorsorgliche Beweissicherung . . . . . . . . . . . . . . . $342 \quad 503$

1. Selbständiges Beweisverfahren . . . . . . . . . . . 343503

2. Privatgutachten . . . . . . . . . . . . . . . 345504 
3. Eidesstattliche Versicherungen . . . . . . . . . . 346505

4. Gedächtnisprotokolle . . . . . . . . . . . . . . . . . 348505

5. Fotografische Dokumentationen. . . . . . . . . . . . . 349506

6. Telefon-Mitschnitte . . . . . . . . . . . . . . . . 350506

Teil 4

Gesellschaftsrechtliche Verträge - Basischeckliste und Kommentierung mit Einzelformulierungsvorschlägen

(Wegmann/von dem Knesebeck)

\section{Vorbereitung von Gesellschaftsverträgen und Konzepten}

I. Konzeptionierung, Vorbemerkungen _ . . . . . . . . . 1508

1. Prämisse . . . . . . . . . . . . . . . . . . 1508

2. Zeitliche Abfolge. . . . . . . . . . . . . . . . $2 \quad 508$

3. Dokumentation . . . . . . . . . . . . . . . . . 3509

II. Rechtliches Konzept . . . . . . . . . . . . . . . . . . . . 4509

1. Entscheidung: Interessenverfolgung durch gemeinsame Gesellschaft. . . . . . . . . . . . . . . . . . 4509

a) Gemeinsame Gesellschaft oder losere Kooperation . . $\quad 5509$

aa) Lose Kooperationsformen ohne Gesellschafts-

bildung. . . . . . . . . . . . . . . . . 6509

(1) Abgestimmte Zulieferungs- und Abnahmeverpflichtungen . . . . . . . . . . . . . $\quad 7 \quad 509$

(2) Dienstvertragsbeziehungen mit Ergebnisbeteiligung, Aktienoptionspläne . . . . . . . $\quad 7 \quad 510$

(3) Partiarische Darlehen . . . . . . . . . . . . $8 \quad 510$

(4) Kartellabsprachen . . . . . . . . . . . . . . 9 9510

bb) Gemeinsame Zweckverfolgung . . . . . . . . . $10 \quad 510$

b) Gemeinsame Gesellschaft möglich . . . . . . . . . . 11511

aa) Wettbewerbsrechtliche Hindernisse . . . . . . . 12511

bb) Berufsrechtliche Hindernisse . . . . . . . . . . . . 13511

cc) Steuerrechtliche Hindernisse . . . . . . . . . . $14 \quad 511$

dd) Kartellrechtliche Hindernisse . . . . . . . . . . . . $15 \quad 512$

2. Interessen und Perspektiven . . . . . . . . . . . . . $16 \quad 512$

a) Zeitliche Dauer des gemeinsamen Engagements . . . . $16 \quad 512$

b) Projektbezug der Gesellschaft . . . . . . . . . . . $17 \quad 512$

c) Engagement der Gesellschafter in der Gesellschaft . . $18 \quad 512$ 
Rz. Seite

aa) Erforderlichkeit aus der Sicht der Gesellschaft und Bereitschaft und Fähigkeit der Gesellschafter . . . $18 \quad 512$

bb) Finanzielles Engagement . . . . . . . . . . . . . . 19513

cc) Tätigkeitsverpflichtungen . . . . . . . . . . . . . 22513

(1) Geschäftsführung und Vertretung . . . . . . . . 22513

(2) Sonstige Tätigkeiten . . . . . . . . . . . . . 23514

dd) Besondere Kenntnisse und Nutzungen . . . . . . . 24514

ee) Außenwirkung des Engagements eines Gesellschafters.......................... 25514

ff) Personenbezug des Engagements . . . . . . . . . . 26514

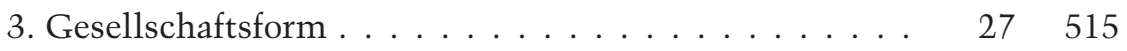

a) Zivilrechtliche Aspekte . . . . . . . . . . . . . . . . . . . . . . . . . 515

aa) Haftung . . . . . . . . . . . . . . . . . . . . . . . . . . . . 515

(1) Haftungsdurchgriff . . . . . . . . . . . . . . $30 \quad 516$

(2) Haftung in der Gründungsphase . . . . . . . . . . 32517

(3) Haftung des GmbH-Geschäftsführers . . . . . $36 \quad 519$

bb) Übertragbarkeit und Vererblichkeit der Gesell-

schafterstellung .................. 37519

cc) Selbstorganschaft/Drittorganschaft . . . . . . 39520

dd) Firma . . . . . . . . . . . . . . . . . . . 40520

ee) Handwerks-GmbH . . . . . . . . . . . . . . 41520

ff) Zulässigkeit von Einmann-Gesellschaften .... $42 \quad 521$

gg) Rechnungslegung und Publizität . . . . . . . 43521

b) Arbeits- und mitbestimmungsrechtliche Aspekte . . 44521

aa) Sozialversicherungspflicht und Altersversorgung. $\quad 44 \quad 521$

bb) Mitbestimmung . . . . . . . . . . . . . . 45522

c) Steuerliche Aspekte . . . . . . . . . . . . . 46522

4. Nutzung vorhandener Unternehmen oder Gesellschaften eines Gesellschafters . . . . . . . . . . . 47523

a) Sinnhaftigkeit der Nutzung. . . . . . . . . . . . . . . 50523

b) Umstrukturierung . . . . . . . . . . . . . . . . . . . . . 51524

a) Rechtsformänderungen . . . . . . . . . . . . . 52524

bb) Beitritt der weiteren Gesellschafter . . . . . . . 53524

III. Betriebswirtschaftliche und steuerliche Prüfung des

Konzepts . . . . . . . . . . . . . . . . . $54 \quad 525$

1. Prüfungsumfang . . . . . . . . . . . . . . $54 \quad 525$

a) Betriebswirtschaftliche Checkliste . . . . . . . $54 \quad 525$

b) Steuerliche Checkliste . . . . . . . . . . . $55 \quad 525$

2. Organisation der Überprüfung . . . . . . . . . . . . . 56526 
a) Interne oder externe Konzeptprüfung . . . . . . . . . . $56 \quad 526$

b) Herbeiführung der Prüfung . . . . . . . . . . . . . . . . . 57526

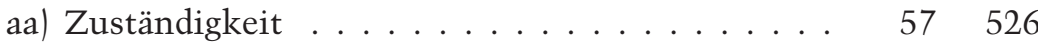

bb) Formulierung. . . . . . . . . . . . . . . . . . $58 \quad 527$

c) Durchführung der Prüfung . . . . . . . . . . . . . . . 59527

d) Rezeption des Prüfungsergebnisses . . . . . . . . . . $60 \quad 527$

IV. Schlusskonzept . . . . . . . . . . . . . . . . . . . . . 61527

\section{Allgemeine Gestaltungsfragen für alle Gesellschaftsverträge}

I. Form des Gesellschaftsvertrags . . . . . . . . . . . . . . $62 \quad 530$

1. Rechtliches Formerfordernis . . . . . . . . . . . . $62 \quad 530$

a) Notarielle Beurkundung bei Gründung einer $\mathrm{GmbH}$ und einer Aktiengesellschaft sowie einer SE . . . . . . $62 \quad 530$

b) Notarielle Beurkundung von Umwandlungen . . . . . $63 \quad 531$

c) Schriftform bei der Partnerschaft . . . . . . . . . . $64 \quad 631$

d) Reduziertes Schriftformerfordernis bei der EWIV . . . $\quad 65 \quad 531$

e) Grundsätzlich Formfreiheit bei sonstigen Gesellschaftsverträgen . . . . . . . . . . . . . . $66 \quad 531$

f) Formbedürftigkeit in Einzelfällen . . . . . . . . . . $67 \quad 531$

aa) Grundbesitz im Gesellschaftsvermögen . . . . . . $68 \quad 631$

bb) Doppelgesellschaften . . . . . . . . . . . . . . . 69532

cc) Auswirkung . . . . . . . . . . . . . . . . . . . . . 70532

2. Urkundliche Gestaltung . . . . . . . . . . . . . . . $71 \quad 532$

II. Beteiligungsfähigkeit in- und ausländischer Gesellschafter und Gesellschaften . . . . . . . . . . . . . . $72 \quad 533$

1. Beteiligungsfähigkeit inländischer Gesellschaften . . . . $72 \quad 533$

a) GbR . . . . . . . . . . . . . . . . . . . . . . $72 \quad 533$

b) oHG, KG . . . . . . . . . . . . . . . . . . . . . $73 \quad 533$

c) $\mathrm{GmbH} \ldots \ldots \ldots$. . . . . . . . . . . . . . . . . . 74533

2. Ausländische natürliche Personen . . . . . . . . . . $75 \quad 533$

3. Ausländische Gesellschaften . . . . . . . . . . . . . 76534

III. Basischeckliste und Aufbauschema für Gesellschaftsverträge . . . . . . . . . . . . . . . . . . . . . . . . . $78 \quad 534$

IV. Kommentierung der Basischeckliste . . . . . . . . . . $79 \quad 535$

1. Vertragliche Grundlagen . . . . . . . . . . . . . . . . 80536

a) Bezeichnung . . . . . . . . . . . . . . . . . . $80 \quad 536$

aa) Vorbemerkungen . . . . . . . . . . . . . $80 \quad 536$

(1) Innengesellschaften . . . . . . . . . . . . . $80 \quad 536$ 
(2) Außengesellschaften . . . . . . . . . . . . . $81 \quad 536$

bb) Grundsätze . . . . . . . . . . . . . . . . . . . . . $84 \quad 537$

cc) Formulierungsbeispiele . . . . . . . . . . . . . $86 \quad 537$

b) Namensrechte (entfällt bei reinen Sachbezeichnungen) . $\quad 87 \quad 537$

aa) Vorbemerkungen . . . . . . . . . . . . . . . . . . $87 \quad 537$

bb) Interessenlage . . . . . . . . . . . . . . . . . . $88 \quad 537$

cc) Formulierungsbeispiele . . . . . . . . . . . . . . 89538

c) $\operatorname{Sitz} \ldots \ldots \ldots \ldots \ldots \ldots$. . . . . . . . . . . . . . . . 91538

aa) Vorbemerkung . . . . . . . . . . . . . . . . 91958

bb) Grundsätze . . . . . . . . . . . . . . . . . . . . . . . . 9295

cc) Vorgreiflichkeit . . . . . . . . . . . . . . . . . 93538

d) Gesellschaftszweck/Unternehmensgegenstand . . . . $94 \quad 539$

aa) Vorbemerkungen . . . . . . . . . . . . . . . . . 94539

bb) Bedeutung . . . . . . . . . . . . . . . . . . . . 95539

(1) Schwerpunkt der Tätigkeit . . . . . . . . . . . $95 \quad 539$

(2) Kompetenz von Gesellschaftsorganen . . . . . . . 96539

(3) Formbedürftigkeit des Gesellschaftsvertrags . . . $97 \quad 539$

cc) Formulierungsbeispiele . . . . . . . . . . . . . . . 9 $98 \quad 540$

e) Gesellschafter, Beteiligungsverhältnisse . . . . . . . . . . $100 \quad 540$

aa) Vorbemerkungen . . . . . . . . . . . . . . . . . . . 100540

(1) Namen der Gesellschafter . . . . . . . . . . . . . $100 \quad 540$

(2) Beteiligungsquote . . . . . . . . . . . . . . . . 102541

f) Besondere Anforderungen an Gesellschafter . . . . . . $103 \quad 541$

aa) Beteiligungsfähigkeit in- und ausländischer

Gesellschafter . . . . . . . . . . . . . . . . . $103 \quad 541$

bb) Gesellschaftsvertragliche Beschränkungen . . . . . . 104541

cc) Formulierungsbeispiele . . . . . . . . . . . . . . . . 105542

g) Gesellschafterstämme/Gesellschaftergruppen . . . . . . $107 \quad 543$

aa) Vorbemerkungen . . . . . . . . . . . . . . . . . . . . . 107543

bb) Formulierungsbeispiele . . . . . . . . . . . . . . . . 109543

h) Dauer der Gesellschaft . . . . . . . . . . . . . . . . . . . . 110544

aa) Vorbemerkungen . . . . . . . . . . . . . . . . . . . . 110544

(1) Bedeutung . . . . . . . . . . . . . . . . . . . . . . 110544

(2) Gestaltung . . . . . . . . . . . . . . . . . . . 111544

bb) Formulierungsbeispiele . . . . . . . . . . . . . . . . $112 \quad 544$

i) Geschäftsjahr . . . . . . . . . . . . . . . . . . . . . . . $114 \quad 544$

aa) Vorbemerkungen . . . . . . . . . . . . . . . . . . . . 114544

bb) Formulierungsbeispiele . . . . . . . . . . . . . . . $115 \quad 545$

j) Kapital der Gesellschaft, Einlagen der Gesellschafter . . $117 \quad 545$ 
aa) Definition . . . . . . . . . . . . . . . . . . . $117 \quad 545$

(1) Beiträge . . . . . . . . . . . . . . . . . . $118 \quad 545$

(2) Einlagen . . . . . . . . . . . . . . . . . . . . $119 \quad 545$

bb) Gestaltung . . . . . . . . . . . . . . . . . . . . . . . 120546

k) Dienstleistungs- und Nutzungsüberlassungspflichten . 121546

aa) Abgrenzung gesellschaftsvertraglicher Pflichten von Leistungspflichten aufgrund zusätzlicher

Abreden . . . . . . . . . . . . . . . . . . . . 121546

bb) Gestaltung . . . . . . . . . . . . . . . . . . . . . . $122 \quad 547$

2. Innere Ordnung der Gesellschaft . . . . . . . . . . . . . 123547

a) Geschäftsführung . . . . . . . . . . . . . . . . . . 123547

aa) Abgrenzung Geschäftsführungsbefugnis Vertretungsmacht. . . . . . . . . . . . . . . . 123547

bb) Kein Recht zur Zwecküberschreitung und zu Grundlagenänderungen . . . . . . . . . . . . . . . $124 \quad 547$

cc) Selbst- und Fremdorganschaft . . . . . . . . . . . . . 125548

b) Buchführung, Bilanzierung . . . . . . . . . . . . . . . . . 127548

aa) Gesetzliche Regelung. . . . . . . . . . . . . . . . . . 127548

bb) Gesellschaftsvertragliche Regelung . . . . . . . . . $128 \quad 548$

c) Kontrollrechte der Gesellschafter . . . . . . . . . . . . . 129549

aa) Gesetzliche Regelung . . . . . . . . . . . . . . . . . . 129549

bb) Gesellschaftsvertraglich mögliche Ergänzungen . . $130 \quad 549$

(1) Beiziehung von Dritten . . . . . . . . . . . . . . 130549

(2) Missbrauchsgefahr . . . . . . . . . . . . . . . . . $131 \quad 549$

d) Gesellschafterversammlung, Stimmrecht,

Einwendungsrechte . . . . . . . . . . . . . . $132 \quad 550$

aa) Gesellschafterversammlung als Entscheidungs-

forum . . . . . . . . . . . . . . . . . 132550

bb) Nähere Gestaltung . . . . . . . . . . . . . . . . . . 134550

e) Ergebnisverwendung . . . . . . . . . . . . . . . . . . $136 \quad 551$

aa) Verluste. . . . . . . . . . . . . . . . . . . . . 136551

(1) Keine Verlustteilnahme bei Kapitalgesellschaften $\quad 136 \quad 551$

(2) Verlustteilnahme bei Personenhandelsgesellschaften, GbR und stiller Gesellschaft . . . . . . $137 \quad 552$

bb) Gewinne . . . . . . . . . . . . . . . . . . . . 138552

f) Wettbewerbsfragen . . . . . . . . . . . . . . . . . 140553

aa) Erforderlichkeit einer Regelung . . . . . . . . . . . . 140553

bb) Interessenlage . . . . . . . . . . . . . . . . . . 141553

cc) Abgrenzung zu arbeitsvertraglichen Wettbewerbsregelungen . . . . . . . . . . . . . . . . . . $142 \quad 554$ 
dd) Gesetzliche Regelungen des Wettbewerbsverbots . 144554

(1) Grundsatz . . . . . . . . . . . . . . . . . . . . . . 144554

(2) GbR . . . . . . . . . . . . . . . . . $145 \quad 554$

(3) oHG . . . . . . . . . . . . . . . . . . . 146554

(4) KG . . . . . . . . . . . . . . . . . . . . . . $148 \quad 555$

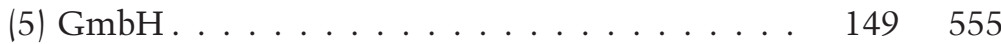

(6) AG . . . . . . . . . . . . . . . . . . . 152556

(7) Weitere Gesellschaften . . . . . . . . . . . . 153557

ee) Verhältnis zum Kartellverbot . . . . . . . . . . . . 154557

ff) Steuerliche Gefahren im Zusammenhang mit dem Wettbewerbsverbot . . . . . . . . . . . . . 155557

gg) Regelungsmöglichkeiten und Regelungsgrenzen . . $157 \quad 558$

hh) Grenzen der Regelungsbefugnis, insbesondere Mandanten- und Branchenschutzklauseln . . . . . $158 \quad 559$

3. Außenverhältnisse der Gesellschaft . . . . . . . . . . . 159559

a) Vertretung der Gesellschaft oder der Gesellschafter . . 159559

aa) Definition . . . . . . . . . . . . . . . . . . 159559

bb) Fremd-/Selbstorganschaft . . . . . . . . . . . . . . . 160560

cc) Vertragliche Regelung . . . . . . . . . . . . . . . 161560

dd) Gestaltung, Adressaten der Vertretungsmacht . . . $162 \quad 560$

ee) Verleihung der Vertretungsmacht, Umfang,

Registrierung, Legitimationsurkunde . . . . . . . 163560

(1) Umfang . . . . . . . . . . . . . . . . . . . . . . . . 164561

(2) Registrierung. . . . . . . . . . . . . . . . . . 165561

(3) Legitimationsurkunde . . . . . . . . . . . . . . 166561

b) Haftungsbeschränkung . . . . . . . . . . . . . . . . . . . 167561

4. Strukturänderungen der Gesellschaft . . . . . . . . . . . 168562

a) Aufnahme weiterer Gesellschafter/Gesellschafterwechsel . . . . . . . . . . . . . . . . . . . . . 168562

aa) Kapitalgesellschaften . . . . . . . . . . . . . . . $168 \quad 562$

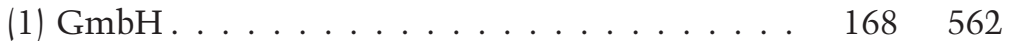

(2) AG . . . . . . . . . . . . . . . . . . . 169562

bb) Personengesellschaften . . . . . . . . . . . . . . . 170563

b) Kündigung eines Gesellschafters . . . . . . . . . . . 171563

aa) Definition . . . . . . . . . . . . . . . . . . 171563

bb) Zulässigkeit . . . . . . . . . . . . . . . . . . . $172 \quad 563$

cc) Form . . . . . . . . . . . . . . . . . . . . . . 173564

dd) Wirkung . . . . . . . . . . . . . . . . . . . . . . . . . 174564

ee) Gestaltung . . . . . . . . . . . . . . . . . . . . . . . . 175564 
(1) Kündbarkeit . . . . . . . . . . . . . . . . . . . . . . $175 \quad 564$

(2) Adressat der Kündigung . . . . . . . . . . . . . . . 176565

(3) Form der Kündigung . . . . . . . . . . . . . . . . 177565

(4) Zeitpunkt der Wirksamkeit der Kündigung . . . . 178565

(5) Folgekündigung . . . . . . . . . . . . . . . . . . . 179566

c) Ausschließung von Gesellschaftern . . . . . . . . . . . . 180566

aa) Vorbemerkungen, Tatbestände . . . . . . . . . . . . . 180566

bb) Gestaltungsrecht der weiteren Gesellschafter . . . . 184567

cc) Regelungsbedarf. . . . . . . . . . . . . . . . . . . . . . 185567

d) Tod eines Gesellschafters . . . . . . . . . . . . . . . . . . 186568

aa) Vorbemerkungen . . . . . . . . . . . . . . . . . . . . . 187568

bb) Gestaltungsüberlegungen . . . . . . . . . . . . . . . . 189568

(1) Bei Personengesellschaften . . . . . . . . . . . $194 \quad 569$

(2) Bei der GmbH und der AG . . . . . . . . . . . 197570

cc) Testamentsvollstreckung . . . . . . . . . . . . . . . . 1985571

(1) Personengesellschaften . . . . . . . . . . . . . 199571

(2) Kapitalgesellschaften . . . . . . . . . . . . . . . 201571

e) Automatisches Ausscheiden . . . . . . . . . . . . . . 201a 571

f) Abfindung . . . . . . . . . . . . . . . . . . 202572

aa) Erforderlichkeit einer Abfindungsregelung . . . . . . 202572

bb) Interessenlage . . . . . . . . . . . . . . . . . . . . 204572

(1) Interesse der Gesellschaft bzw. der Mitgesellschafter bzw. eintrittswilliger Dritter . . . . . . . 205572

(2) Interessenlage des Gesellschafters bzw. sonstiger Dritter . . . . . . . . . . . . . . 206572

(3) Abfindungsklausel zur Streitverhütung . . . . . . $207 \quad 573$

(4) Differenzierungsmöglichkeiten . . . . . . . . . . 208573

(5) Möglichkeiten . . . . . . . . . . . . . . . . . . . 209573

cc) Beurteilung von Abfindungsklauseln durch die

Rechtsprechung . . . . . . . . . . . . . . . 210574

dd) Rechtsfolgen. . . . . . . . . . . . . . . . . . . . . 211575

ee) Differenzierungskriterien . . . . . . . . . . . . . . 212575

ff) Insbesondere: Abfindung nach dem „Stuttgarter Verfahren" ................... 213576

gg) Zusammenhang der Abfindungsregelung mit Kapitalkonten . . . . . . . . . . . . . . . . . . 215577

hh) Erb- und familienrechtliche Auswirkungen von Abfindungsklauseln . . . . . . . . . . . . . . . 216577

g) Weitere Ansprüche des ausscheidenden Gesellschafters $219 \quad 578$ 
Rz. Seite

aa) Rückgewähr von Gegenständen, die ein Gesellschaf-

ter der Gesellschaft zur Nutzung überlassen hat . . 220578

bb) Befreiung von Schulden bzw. Sicherheitsleistung . 221579

cc) Gestaltungsüberlegungen . . . . . . . . . . . 222579

(1) Rückgewähr von Gegenständen, die zur

Nutzung überlassen wurden . . . . . . . . . . . 222579

(2) Befreiung von Schulden bzw. Sicherheitsleistung $223 \quad 579$

h) Nebenansprüche beim Ausscheiden . . . . . . . . . 224580

a) Vertraulichkeit ..................... 224580

bb) Herausgabe von Unterlagen . . . . . . . . . . . 225580

5. Allgemeine Bestimmungen . . . . . . . . . . . . . . . 226580

a) Sonstige Bestimmungen . . . . . . . . . . . . 226580

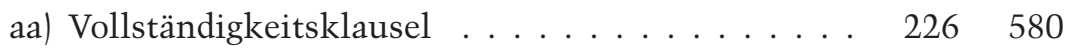

bb) Vertragsänderungen . . . . . . . . . . . . . 227580

b) Teilnichtigkeit .................. 228581

\section{Gestaltungsfragen bei einzelnen Gesellschaftsverträgen}

I. Gesellschaft des bürgerlichen Rechts . . . . . . . . . . . . 229587

1. Vertragliche Grundlagen . . . . . . . . . . . . . . . . . . . . 229587

a) Bezeichnung . . . . . . . . . . . . . . . . . . . . . . . . . . . . . . . . . 589

aa) Innengesellschaften . . . . . . . . . . . . . . . 229587

bb) Außengesellschaften . . . . . . . . . . . . . . . . . . 230 587

cc) Formulierungsbeispiele . . . . . . . . . . . 231588

(1) Grundstücksverwaltende Gesellschaft mit

Sachbezeichnung .............. 231588

(2) Gewerblich tätige Gesellschaft mit gemischter

Sach- und Namensbezeichnung . . . . . . . . 231a 588

b) Namensrechte . . . . . . . . . . . . . . . . . . . . . . . . . . . . . . . . 23258

c) $\operatorname{Sitz\ldots \ldots \ldots \ldots \ldots \ldots \ldots \ldots } 23358 \ldots \ldots$

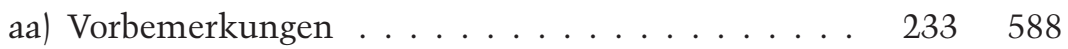

bb) Formulierungsbeispiele . . . . . . . . . . . . 234588

d) Gesellschaftszweck/Unternehmensgegenstand . . . . . 235589

e) Gesellschafter, Beteiligungsverhältnis . . . . . . . . . . 236589

aa) Vorbemerkungen . . . . . . . . . . . . . . . . . . . 236589

bb) Formulierungsbeispiele . . . . . . . . . . . 23758

f) Besondere Anforderungen an Gesellschafter . . . . . . . 238590

g) Gesellschafterstämme/Gesellschaftergruppen . . . . . 239590

aa) Vorbemerkungen . . . . . . . . . . . . . . . . . . . . 239590

bb) Formulierungsbeispiel . . . . . . . . . . . . 24059 
h) Dauer der Gesellschaft . . . . . . . . . . . . . . . . . . . $241 \quad 591$

i) Geschäftsjahr. . . . . . . . . . . . . . . . . . . . $242 \quad 591$

j) Kapital der Gesellschaft, Einlagen der Gesellschafter . $243 \quad 591$

k) Dienstleistungs- und Nutzungsüberlassungspflichten . $244 \quad 592$

2. Innere Ordnung der Gesellschaft . . . . . . . . . . . . . . 247593

a) Geschäftsführung . . . . . . . . . . . . . . . . . . . . 247593

aa) Vorbemerkungen . . . . . . . . . . . . . . . . . . . 247593

bb) Gestaltung . . . . . . . . . . . . . . . . . . . . . . . . 248593

(1) Geschäftsleitung durch Nichtgesellschafter trotz Selbstorganschaft . . . . . . . . . . . . . 249593

(2) Geschäftsführung durch einzelne Gesellschafter $250 \quad 594$

cc) Formulierungsbeispiele . . . . . . . . . . . . . . . 251594

(1) Gesellschaft mit gesellschaftsfremdem Geschäftsleiter. . . . . . . . . . . . . . . 251594

(2) Gesellschafterinterne Geschäftsführung . . . . 252595

(3) Geschäftsführung bei Freiberufler-GbR . . . . . 252a 595

b) Buchführung, Bilanzierung . . . . . . . . . . . . . . . . 253595

aa) Vorbemerkungen . . . . . . . . . . . . . . . . . . 253595

bb) Formulierungsbeispiele . . . . . . . . . . . . . . 254596

c) Kontrollrechte der Gesellschafter . . . . . . . . . . . . . 255596

aa) Vorbemerkungen . . . . . . . . . . . . . . . . 255596

bb) Formulierungsbeispiel . . . . . . . . . . . . . . . 256596

d) Gesellschafterversammlung, Stimmrecht,

Einwendungsrechte . . . . . . . . . . . . . . . 257596

aa) Vorbemerkungen . . . . . . . . . . . . . . . . . . . 257596

bb) Formulierungsbeispiel . . . . . . . . . . . . . . . . 258597

e) Ergebnisverwendung . . . . . . . . . . . . . . . . . . . . 259598

aa) Vorbemerkungen . . . . . . . . . . . . . . . . . . 259598

(1) Verweisung . . . . . . . . . . . . . . . . . . . . . . 259598

(2) Gesetzliche Regelung . . . . . . . . . . . . . . . 260598

bb) Vertragsgestaltung . . . . . . . . . . . . . . . . . . 261598

(1) Rücklagenbildung durch Gewinnthesaurierung 261598

(2) Bewältigung von Verlusten . . . . . . . . . . 262599

cc) Formulierungsbeispiel . . . . . . . . . . . . . . . . . 263600

f) Wettbewerbsfragen . . . . . . . . . . . . . . . . . . 264601

aa) Vorbemerkungen . . . . . . . . . . . . . . . . . . 264601

bb) Gestaltung . . . . . . . . . . . . . . . . . . . . . . . . 265601

cc) Formulierungsbeispiele . . . . . . . . . . . . . . $266 \quad 602$

3. Außenverhältnisse der Gesellschaft (Vertretung,

Haftungsbeschränkung) . . . . . . . . . . . . . . . . 268603 
a) Verweisung. . . . . . . . . . . . . . . . . . . . . . 268603

b) Gesetzliche Regelung . . . . . . . . . . . . . . . . . 269603

aa) Umfang der Vertretungsmacht außerhalb des

Grundbuchverkehrs .............. 270603

bb) Legitimationsnachweis . . . . . . . . . . . . . . . 271603

cc) Vertretung im Grundbuchverkehr, Nachweis . . . 272604

c) Formulierungsbeispiele . . . . . . . . . . . . . . . . 273604

aa) Vertretungsmacht ohne Haftungsauftrag . . . . . . 273604

bb) Vertretungsmacht einer GbR mit Haftungsbegrenzungsauftrag. . . . . . . . . . . . . 274604

4. Strukturänderungen der Gesellschaft . . . . . . . . . 275605

a) Aufnahme weiterer Gesellschafter/Gesellschafterwechsel . . . . . . . . . . . . . . . 275605

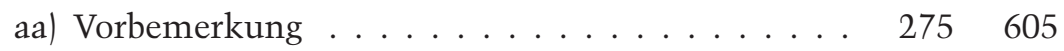

bb) Gestaltung. . . . . . . . . . . . . . . 276605

cc) Formulierungsbeispiele . . . . . . . . . . . . . . . 277606

b) Kündigung eines Gesellschafters . . . . . . . . . . . . 278606

aa) Vorbemerkung .................. 278606

bb) Gesetzliche Regelung und Regelbarkeit . . . . . . . 279606

cc) Formulierungsbeispiele . . . . . . . . . . . . . . . . 280 607

c) Ausschließung von Gesellschaftern . . . . . . . . . . . . . . . 282608

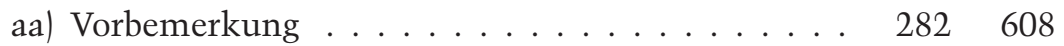

bb) Formulierungsbeispiel . . . . . . . . . . . . . . 283608

d) Tod eines Gesellschafters . . . . . . . . . . . . . . . . . . . . 284 609

aa) Vorbemerkung . . . . . . . . . . . . . . . . . . . . . . 284609

bb) Gestaltung . . . . . . . . . . . . . . . . . . . . . . . . . . . . . . . . . . . 685

cc) Formulierungsbeispiele . . . . . . . . . . . . . . . 286610

e) Abfindung . . . . . . . . . . . . . . . . . . . . . . . . . . . . . . . . . 610

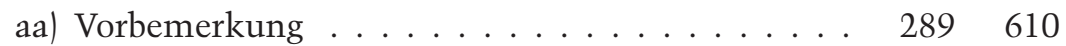

bb) Gestaltung . . . . . . . . . . . . . . . . . . . . . 290610

cc) Formulierungsbeispiele . . . . . . . . . . . . 291611

f) Anmietungs- und Ankaufsrecht, weitere Ansprüche beim Ausscheiden . . . . . . . . . . . . . . 293612

g) Sonstige Bestimmungen . . . . . . . . . . . . . . 294613

II. Offene Handelsgesellschaft . . . . . . . . . . . . . . . 295613

1. Vertragliche Grundlagen, Vorbemerkungen . . . . . . . . 295613

2. Zweck: Betrieb eines Gewerbes bzw. vermögens-

verwaltende Tätigkeit . . . . . . . . . . . . . . . . . . . 296613

3. Firma . . . . . . . . . . . . . . . . 298614 
4. Sitz der Gesellschaft, inländische Geschäftsanschrift . . $301 \quad 615$

5. Gegenstand des Unternehmens . . . . . . . . . . . . 302616

6. Rechte und Pflichten der Gesellschafter, insbesondere Stimmrecht . . . . . . . . . . . . . . . . 303616

a) Vorbemerkung . . . . . . . . . . . . . . . . . . . . . . 303616

b) Gestaltung. . . . . . . . . . . . . . . . . . . . . . . . . $304 \quad 617$

7. Informationsrecht . . . . . . . . . . . . . . . . . . . . 308618

8. Wettbewerbsverbot . . . . . . . . . . . . . . 309618

9. Grundsatz der rechtlichen Selbständigkeit . . . . . . . 310618

10. Beitragsleistung . . . . . . . . . . . . . . . . . $311 \quad 619$

a) Gegenstand der „Beiträge“, Umfang und Bewertung . 311619

b) Leistungsstörungen bei der Einlageerbringung. . . . . $315 \quad 620$

11. Kapitalanteil und Gesellschafterkonten . . . . . . . . . $318 \quad 620$

a) Gesetzliche Regelung . . . . . . . . . . . . . . . . . . $318 \quad 620$

b) Gestaltung. . . . . . . . . . . . . . . . . . . . . . . . . . 319621

12. Entnahmen . . . . . . . . . . . . . . . . . . . $321 \quad 622$

13. Buchführung und Bilanzierung, Jahresabschluss . . . . . $322 \quad 623$

14. Geschäftsführung . . . . . . . . . . . . . . . . . 323623

15. Vertretung . . . . . . . . . . . . . . . . . . . . 324624

16. Verfügung über den Gesellschaftsanteil . . . . . . . . . $325 \quad 625$

17. Tod eines Gesellschafters . . . . . . . . . . . . . . . . $326 \quad 625$

18. Abfindung . . . . . . . . . . . . . . . . $327 \quad 625$

III. Partnerschaftsgesellschaft . . . . . . . . . . . . . . . . $328 \quad 625$

1. Vor- und Nachteile der Partnerschaft . . . . . . . . . . . . 329625

2. Rechte und Pflichten der Gesellschafter . . . . . . . . . $330 \quad 626$

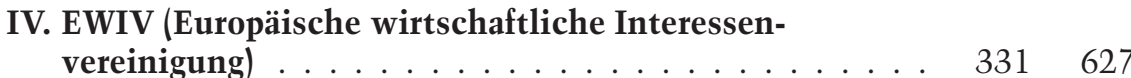

1. Vorbemerkungen . . . . . . . . . . . . . . . . . . $331 \quad 627$

2. Vertragliche Grundlage . . . . . . . . . . . . . . . . . . 332627

3. Rechte und Pflichten . . . . . . . . . . . . . . . . 333628

4. Geschäftsführung und Vertretung . . . . . . . . . . . . $334 \quad 628$

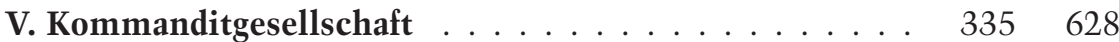

1. Gesellschaftszweck . . . . . . . . . . . . . . . . 335628

2. Firma, Sitz, inländische Geschäftsanschrift . . . . . . . $336 \quad 628$

3. Geschäftsführung und Widerspruchsrecht der Kommanditisten . . . . . . . . . . . . . . . . . . . 338629

4. Stimmrecht-Gesellschafterbeschlüsse . . . . . . . . . . $340 \quad 630$

5. Informationsrecht . . . . . . . . . . . . . . . . $341 \quad 630$ 
6. Vertragliche Änderungen der Kontrollrechte der

Rz. Seite

Kommanditisten . . . . . . . . . . . . . . . . . . . . $342 \quad 631$

7. Wettbewerbsverbot . . . . . . . . . . . . . . . 343631

8. Haftung der Kommanditisten . . . . . . . . . . . . . . 344631

a) Vorbemerkung . . . . . . . . . . . . . . . . . . . . . . . 344631

aa) Pflichteinlage. . . . . . . . . . . . . . . 345631

bb) Haftsumme . . . . . . . . . . . . . . . . . . . . . $346 \quad 631$

b) Gestaltung. . . . . . . . . . . . . . . . . . . . 347632

aa) Wiederaufleben der Haftung bei Rückzahlung der Haftsumme . . . . . . . . . . . . . . . . . . $348 \quad 632$

bb) Haftung vor Eintragung . . . . . . . . . . . . . . . . 349633

9. Gewinn und Verlust . . . . . . . . . . . . . . . . . . . 350633

10. Entnahmen, Buchführung und Bilanzierung . . . . . 351633

11. Vertretung der Gesellschaft nach außen . . . . . . . . . $352 \quad 633$

12. Strukturänderungen der Gesellschaft . . . . . . . . . $353 \quad 634$

a) Vorbemerkung . . . . . . . . . . . . . . . . . . . . . . . 353634

b) Gestaltung. . . . . . . . . . . . . . . . . . . . . . . . . 354634

aa) (Isolierter) Beitritt bzw. Ausscheiden eines Gesellschafters . . . . . . . . . . . . . . . . . . 354634

bb) Gesellschafterwechsel - Übertragung eines Kommanditanteils unter Lebenden . . . . . . . . . $356 \quad 635$

cc) Umwandlung der Gesellschafterstellung (Komplementär in Kommanditist bzw. umgekehrt) . . . . $358 \quad 635$

dd) Schenkungen, insbesondere im Rahmen einer vorweggenommenen Erbfolge . . . . . . . . . . 359636

13. Beendigung der Gesellschaft . . . . . . . . . . . . . . . 361637

VI. Stille Gesellschaft, Unterbeteiligung . . . . . . . . . . . . $362 \quad 637$

1. Stille Gesellschaft . . . . . . . . . . . . . . . . . . . . . $362 \quad 637$

a) Gesetzliche Regelung . . . . . . . . . . . . . . . . . . 362637

b) Gestaltung. . . . . . . . . . . . . . . . . . . . . . . . 365638

aa) Anwendungsbereich . . . . . . . . . . . . . . 365638

bb) Rechte und Pflichten der Gesellschafter . . . . . . $367 \quad 639$

(1) Leistung der Einlage . . . . . . . . . . . . . . $367 \quad 639$

(2) Gewinn- und Verlustbeteiligung . . . . . . . . $368 \quad 639$

(3) Kontroll- und Überwachungsrechte . . . . . . . $370 \quad 640$

(4) Haftung . . . . . . . . . . . . . . . . . . . . . 371640

cc) Innere Organisation . . . . . . . . . . . . . . $372 \quad 640$

dd) Vertretung der Gesellschaft nach außen . . . . . . $373 \quad 641$

ee) Strukturänderungen der Gesellschaft . . . . . . . . $374 \quad 641$

ff) Beendigung der Gesellschaft . . . . . . . . . . . $376 \quad 641$ 
(1) Auflösung . . . . . . . . . . . . . . . . . . . . . $376 \quad 641$

(2) Auseinandersetzung . . . . . . . . . . . . . . $377 \quad 642$

2. Unterbeteiligung . . . . . . . . . . . . . . . . . . . $380 \quad 643$

a) Begriff, Formen, Vor- und Nachteile . . . . . . . . . . 380643

b) Rechte und Pflichten der Gesellschafter . . . . . . . 383644

c) Geschäftsführung und Vertretung . . . . . . . . . . . $386 \quad 645$

d) Kontroll- und Informationsrechte . . . . . . . . . . . $387 \quad 646$

e) Wechsel des Unterbeteiligten . . . . . . . . . . . . . . 388646

f) Beendigung der Gesellschaft, Auseinandersetzung . 389646

g) Sonstige Auflösungsgründe . . . . . . . . . . . . . . . 390647

h) Auseinandersetzung, Vermögensbeteiligung . . . . . 391647

i) Allgemeine Bestimmungen . . . . . . . . . . . . . . . 394647

VII. GmbH/UG (haftungsbeschränkt) . . . . . . . . . . . . 394a 648

1. Vorbemerkungen. . . . . . . . . . . . . . . . . . . 394a 648

2. Vertragliche Grundlagen . . . . . . . . . . . . . . . . . . 395648

a) Firma . . . . . . . . . . . . . . . . . . . . . . . 395648

aa) Vorbemerkung . . . . . . . . . . . . . . . . . . . 395648

bb) Grundsätze . . . . . . . . . . . . . . . . . . . . . $396 \quad 648$

cc) Formulierungsbeispiele . . . . . . . . . . . . . . 397649

b) Namensrechte. . . . . . . . . . . . . . . . . . . . . . 398650

aa) Vorbemerkung . . . . . . . . . . . . . . . . . . . 398650

bb) Formulierungsbeispiel . . . . . . . . . . . . . . . 399650

c) Sitz, inländische Geschäftsanschrift . . . . . . . . . . 400650

aa) Vorbemerkung . . . . . . . . . . . . . . $400 \quad 650$

bb) Formulierungsbeispiel . . . . . . . . . . . . . . . . 401650

d) Unternehmensgegenstand . . . . . . . . . . . . . . . $402 \quad 650$

aa) Vorbemerkung . . . . . . . . . . . . . . . . . 402650

bb) Verweisung . . . . . . . . . . . . . . . . . . $403 \quad 651$

e) Stammkapital . . . . . . . . . . . . . . . . . . . . . . . $404 \quad 651$

aa) Vorbemerkung . . . . . . . . . . . . . . . . . . $404 \quad 651$

bb) Formulierungsbeispiel. . . . . . . . . . . . . . . . $406 \quad 651$

f) Gesellschafter, Einlagen . . . . . . . . . . . . . . 407651

aa) Gesetzliche Regelung . . . . . . . . . . . . . . . 407651

bb) Formulierungsbeispiel . . . . . . . . . . . . . . . . $408 \quad 652$

g) Bareinlage oder Sacheinlage . . . . . . . . . . . . . . . 409652

aa) Vorbemerkung . . . . . . . . . . . . . . . . . . 409652

bb) Bareinlage . . . . . . . . . . . . . . . . . . . . . . 410652

cc) Sacheinlage . . . . . . . . . . . . . . . . . . 411653

dd) Mischeinlagen . . . . . . . . . . . . . . . . . . $412 \quad 653$ 
ee) Fälligkeit der Einlageverpflichtung . . . . . . . . . . $413 \quad 653$

h) Gesellschafterstämme, Gesellschaftergruppen . . . . . $414 \quad 654$

aa) Vorbemerkung . . . . . . . . . . . . . . . . . . . . . 414654

bb) Formulierungsbeispiel . . . . . . . . . . . . . . . . 415654

3. Evtl. gruppenbezogene Sonderrechte . . . . . . . . . . . $416 \quad 654$

a) Dauer der Gesellschaft . . . . . . . . . . . . . . . . . . . $416 \quad 654$

b) Geschäftsjahr . . . . . . . . . . . . . . . . . . . . . . $417 \quad 654$

c) Dienstleistungs- und Nutzungsüberlassungspflichten . $418 \quad 655$

4. Innere Ordnung und Außenverhältnisse der Gesellschaft $419 \quad 655$

a) Geschäftsführung und Vertretung . . . . . . . . . . . . . 419655

aa) Vorbemerkung. . . . . . . . . . . . . . . . . . . 419655

(1) Vertretung . . . . . . . . . . . . . . . . . . . . $420 \quad 655$

(2) Geschäftsführung . . . . . . . . . . . . . . $422 \quad 656$

bb) Formulierungsbeispiele . . . . . . . . . . . . . . 423656

b) Buchführung, Bilanzierung . . . . . . . . . . . . . . . 425657

aa) Vorbemerkung . . . . . . . . . . . . . . . . . . . . 425657

bb) Formulierungsbeispiel . . . . . . . . . . . . . . $426 \quad 657$

c) Kontrollrechte der Gesellschafter . . . . . . . . . . . . . 427657

d) Gesellschafterversammlung, Stimmrechte,

Einwendungsrechte . . . . . . . . . . . . . . . . 428658

aa) Verweisung. . . . . . . . . . . . . . . . . . . . . 428658

bb) Formulierungsbeispiel . . . . . . . . . . . . . . . . . . . . 429658

e) Ergebnisverwendung . . . . . . . . . . . . . . . . . . . . 430659

aa) Vorbemerkung. . . . . . . . . . . . . . . . . . 430659

(1) Verluste . . . . . . . . . . . . . . . . . . . . . $430 \quad 659$

(2) Gewinne . . . . . . . . . . . . . . . $431 \quad 659$

bb) Formulierungsbeispiel . . . . . . . . . . . . . . . . 432659

f) Wettbewerb . . . . . . . . . . . . . . . . . $433 \quad 660$

aa) Vorbemerkung. . . . . . . . . . . . . . . . . . 433660

bb) Formulierungsbeispiel . . . . . . . . . . . . . . . . . . $434 \quad 660$

5. Strukturänderungen der Gesellschaft . . . . . . . . . . 435661

a) Verfügung über Geschäftsanteile . . . . . . . . . . . . . . . $435 \quad 661$

aa) Vorbemerkung . . . . . . . . . . . . . . . . . . 435661

bb) Gestaltung . . . . . . . . . . . . . . . . . . . $436 \quad 661$

cc) Formulierungsbeispiele . . . . . . . . . . . . . . 438662

b) Kündigung durch den Gesellschafter . . . . . . . . . . $440 \quad 663$

c) Ausschließung von Gesellschaftern . . . . . . . . . . 441663

aa) Vorbemerkungen . . . . . . . . . . . . . . . 441663 
bb) Gestaltung . . . . . . . . . . . . . . . . . . . . . 442664

cc) Formulierungsbeispiel. . . . . . . . . . . . . . . . 444665

d) Tod des Gesellschafters . . . . . . . . . . . . . . . . . $445 \quad 665$

e) Abfindung . . . . . . . . . . . . . . . . . . . . $446 \quad 666$

6. Allgemeine Bestimmungen . . . . . . . . . . . 447666

VIII. GmbH \& Co. KG . . . . . . . . . . . . . . . . . . . $448 \quad 666$

1. Vorbemerkung und Erscheinungsformen . . . . . . . 448666

a) Vorbemerkung . . . . . . . . . . . . . . . . . . . . 448666

b) Erscheinungsformen . . . . . . . . . . . . . . . . . . . 449667

aa) Typische GmbH \& Co. KG . . . . . . . . . . . 449667

bb) Beteiligungsidentische GmbH \& Co. KG . . . . . 450667

cc) Einheits-GmbH \& Co. KG . . . . . . . . . . . 451667

dd) Publikums-GmbH \& Co. KG . . . . . . . . . . . . 452668

2. Gestaltungsfragen außerhalb der „Verzahnungsproblematik" . . . . . . . . . . . . . . . 453668

a) Firmierung bei GmbH und bei KG . . . . . . . . . . . 454668

aa) Vorbemerkung . . . . . . . . . . . . . . . . . . 454668

bb) Formulierungsbeispiele . . . . . . . . . . . . . . . 455669

b) Unternehmensgegenstand . . . . . . . . . . . . . . . 456669

aa) Vorbemerkung . . . . . . . . . . . . . . . . . 456669

bb) Formulierungsbeispiele . . . . . . . . . . . . . 457669

c) Befreiung von $\S 181$ BGB . . . . . . . . . . . . . . . $458 \quad 670$

aa) Vorbemerkung . . . . . . . . . . . . . . . . . 458670

bb) Gestaltungsgrundsätze . . . . . . . . . . . . . . . 459670

cc) Formulierungsbeispiele . . . . . . . . . . . . . 460670

dd) Handelsregisteranmeldung und -eintragung . . . $462 \quad 671$

3. Verzahnung der Beteiligungen bei der $\mathrm{GmbH}$ und der KG . . . . . . . . . . . . . . . . . . . . . . 463671

a) Identitätsgrundsatz . . . . . . . . . . . . . . . . . 465672

b) Ergänzung der Bestimmungen betr. die Verfügung über Geschäftsanteile/Beteiligungen . . . . . . . . . $466 \quad 673$

aa) Vorbemerkung . . . . . . . . . . . . . . . $466 \quad 673$

bb) Freie Veräußerlichkeit der Beteiligungen gewünscht. . . . . . . . . . . . . . . $467 \quad 673$

cc) Eingeschränkte Veräußerlichkeit gewünscht . . $468 \quad 673$

dd) Ankaufs- und Vorkaufsrechte . . . . . . . . . . . 469673

c) Formulierungsbeispiele . . . . . . . . . . . . . . . 470674

aa) Sonst freie Veräußerlichkeit des Geschäftsanteils und der Beteiligung . . . . . . . . . . . $470 \quad 674$ 
bb) Sonst bestehendes Vorkaufsrecht bei der Veräußerung des Geschäftsanteils/der Beteiligung . . . . . . $472 \quad 674$

cc) Anbietungspflicht mit Ankaufsrecht . . . . . . . 474674

d) Ergänzung der Bestimmungen beim Tod des

Gesellschafters . . . . . . . . . . . . . . $475 \quad 675$

aa) Bei sonst freier Vererblichkeit . . . . . . . . . . . $475 \quad 675$

bb) Qualifizierte Nachfolgeregelung . . . . . . . . $476 \quad 675$

(1) Qualifizierte Nachfolgeregelung bei der GmbH $477 \quad 675$

(2) Regelung des Scheiterns . . . . . . . . . . $478 \quad 676$

e) Ergänzung der Bestimmungen beim Zwangs-

ausscheiden . . . . . . . . . . . . . . . . . . . 479676

IX. AG, insbesondere kleine AG . . . . . . . . . . . . . $480 \quad 676$

1. Allgemeine Vorbemerkungen . . . . . . . . . . . . . $480 \quad 676$

a) Grundlagen, SE als Gestaltungsalternative . . . . . . . 480676

b) "Kleine $\mathrm{AG}^{\prime \prime} \ldots \ldots \ldots$. . . . . . . . . . . . . . . . 481677

c) Gründe für die AG . . . . . . . . . . . . . . . . . . . $482 \quad 677$

d) Personalistische, insb. Familien-AG . . . . . . . . $484 \quad 678$

aa) Personalisierung durch satzungs- und schuld-

rechtliche Abreden . . . . . . . . . . . . . . . . . 484678

bb) Beispiele. . . . . . . . . . . . . . . . . . . 485678

cc) Sicherung des Fortbestands der schuldrechtlichen

Abreden bei Einzelrechtsnachfolge . . . . . . . . . . $486 \quad 678$

dd) Vinkulierte Namensaktien . . . . . . . . . . . . . 486a 679

ee) Formulierungsbeispiele . . . . . . . . . . . . . . . 487679

(1) Ankaufsrecht . . . . . . . . . . . . . . . . . 487679

(2) Vertragsstrafe . . . . . . . . . . . . . . . . $488 \quad 679$

(3) Vinkulierte Namensaktien . . . . . . . . . . . 488a 679

e) Vorbemerkungen zur folgenden Checkliste . . . . . 489679

2. Vertragliche Grundlagen . . . . . . . . . . . . . . . . . 490680

a) Firma . . . . . . . . . . . . . . . . . . . . 490680

aa) Verweisung . . . . . . . . . . . . . . . . . . . . . 490680

bb) Rechtsnatur . . . . . . . . . . . . . . . . $491 \quad 680$

b) Namensrechte . . . . . . . . . . . . . . . . . . . . . . . 492680

aa) Verweisung . . . . . . . . . . . . . . . . . . . . . . . . . 492680

bb) Rechtsnatur . . . . . . . . . . . . . . . . . . . . 493680

c) Sitz; inländische Geschäftsanschrift . . . . . . . . . $494 \quad 680$

aa) Verweisung . . . . . . . . . . . . . . . . . . . . . 494680

bb) Rechtsnatur . . . . . . . . . . . . . . . . 495680

d) Unternehmensgegenstand . . . . . . . . . . . . . . $496 \quad 680$ 
aa) Verweisung . . . . . . . . . . . . . 496680

bb) Aktienrechtliche Besonderheiten . . . . . . . . . . . 497681

cc) Formulierungsbeispiel . . . . . . . . . . . . . . . . . . . 499681

dd) Rechtsnatur . . . . . . . . . . . . . . . . . . 500681

e) Grundkapital . . . . . . . . . . . . . . . . . . . . . . . . 501681

a) Verweisung, Vorbemerkungen ........... . . . . . . 501681

bb) Rechtsnatur . . . . . . . . . . . . . . . . . 502681

f) Einteilung des Grundkapitals . . . . . . . . . . . . . . . . . . . 503682

aa) Vorbemerkungen . . . . . . . . . . . . . 503682

bb) Nennbetragsaktien . . . . . . . . . . . . . . . . . . . 504682

cc) Stückaktien . . . . . . . . . . . . . . . . 505682

dd) Formulierungsbeispiele . . . . . . . . . . . . . 506682

(1) Nennbetragsaktien . . . . . . . . . . . . . 506682

(2) Stückaktien ................. . . 506682

ee) Rechtsnatur . . . . . . . . . . . . . . . . . 507682

g) Inhaber- oder Namensaktien . . . . . . . . . . . . . . . . . . . . 508682

aa) Grundsätzliches Wahlrecht . . . . . . . . . . . . . 508682

bb) Unterschiede zwischen Namens- und Inhaberaktien 509683

cc) Formulierungsbeispiele . . . . . . . . . . . . 510683

h) Gesellschafter, Einlagen . . . . . . . . . . . . . . . 511684

aa) Gesetzliche Regelung . . . . . . . . . . . . . . 511684

bb) Formulierungsbeispiele . . . . . . . . . . . . . 512684

i) Bareinlagen, Sacheinlagen, Sachübernahmen . . . . . . . . . 513684

aa) Vorbemerkungen . . . . . . . . . . . . . . . 513684

bb) Formulierungsbeispiel . . . . . . . . . . . . . . 514685

j) Fälligkeit der Einlageverpflichtungen . . . . . . . . . 515685

aa) Vorbemerkungen . . . . . . . . . . . . . 515685

bb) Satzungsgestaltung . . . . . . . . . . . . $516 \quad 685$

c) Formulierungsbeispiele . . . . . . . . . . . . 517686

k) Gesellschafterstämme/Gesellschaftergruppen . . . . . . 518686

a) Vorbemerkungen, Verweisung ........... 518686

bb) Formulierungsbeispiel . . . . . . . . . . . . . . . . 519686

cc) Eingeschränkte satzungsmäßige Gestaltungs-

möglichkeiten . . . . . . . . . . . . . 520687

(1) Einfluss auf die Organbesetzung . . . . . . . . . 520687

(2) Formulierungsbeispiele . . . . . . . . . . . . 521687

(a) Entsendungsrecht in den Aufsichtsrat . . . . . 521687

(b) Vinkulierung mit Gruppierung . . . . . . . . . . . . 521687

(c) Sonstige Übertragungen . . . . . . . . . . . . 521688 
1) Dauer der Gesellschaft . . . . . . . . . . . . . . . . . . . . 522688

m) Geschäftsjahr . . . . . . . . . . . . . . . . . 523688

n) Dienstleistungs- und Nutzungsüberlassungsverpflichtungen . . . . . . . . . . . . . 524688

3. Ordnung der Außenverhältnisse der Gesellschaft . . . . . 525688

a) Geschäftsführung und Vertretung . . . . . . . . . . . . . 525688

aa) Vorbemerkungen . . . . . . . . . . . . . 525688

bb| Vertretung . . . . . . . . . . . . . . . . . . . . 526688

cc) Geschäftsführung . . . . . . . . . . . . . . 527689

dd) Formulierungsbeispiele . . . . . . . . . . . . . . . . 528690

b) Buchführung, Bilanzierung . . . . . . . . . . . . . . . . . . 530690

c) Kontrollorgan Aufsichtsrat ............. . . . . . . . 531691

aa) Grundlagen . . . . . . . . . . . . . . . . . 531691

bb) Satzungsbestimmungen . . . . . . . . . . . . . . 532691

cc) Formulierungsbeispiel zum Aufsichtsrat . . . . . . 533692

dd) Kontrolle durch die Gesellschafter . . . . . . . . . 534693

d) Hauptversammlung, Stimmrechte, Einwendungsrechte 535693

aa) Grundlagen, Verweisung ............ 535693

bb) Formulierungsbeispiel (nicht börsennotierte

Gesellschaft) . . . . . . . . . . . 536694

e) Ergebnisverwendung . . . . . . . . . . . . . . . . . . . . . . . . . . . . . . . . 537694

aa) Verweisung . . . . . . . . . . . . . . . 537694

bb) Formulierungsbeispiel . . . . . . . . . . . . . . . . . 538695

4. Strukturänderungen der Gesellschaft . . . . . . . . . . . . 539695

a) Verfügungen über Aktien . . . . . . . . . . . . . . . . . . . . . . . . . 539695

b) Ausschließung von Gesellschaftern . . . . . . . . . . 540695

c) Tod eines Gesellschafters . . . . . . . . . . . . . . . . . . 541696

d) Abfindung . . . . . . . . . . . . . . . . . . 542696

e) Sonstige Bestimmungen . . . . . . . . . . . . . . 543697

X. Europäische Aktiengesellschaft (Societas Europea - SE) . 544697

1. Rechtliche Grundlagen . . . . . . . . . . . . . . . . . . . . . . . . 544697

2. Gründe für eine SE . . . . . . . . . . . . . . . . . . . . 545698

a) Schaffung einer einheitlichen Konzernstruktur . . . . $546 \quad 698$

b) Vereinfache Sitzverlegung . . . . . . . . . . . . . . . 547698

c) Möglichkeit der grenzüberschreitenden Verschmelzung $548 \quad 698$

d) Europa-AG als europäische Marke . . . . . . . . . . . . 549698

3. Gründungsformen . . . . . . . . . . . . . . . . . . . . . . . . . . . . . . 550698

a) Verschmelzung . . . . . . . . . . . . . . . . . . . . . . 551699

b) Holding SE . . . . . . . . . . . . . . . . . . 552699 
c) Tochter-SE . . . . . . . . . . . . . . . . . . . . . . . . . 553699

d) Umwandlung . . . . . . . . . . . . . . . . . . . . . . . . 554699

4. Organisationsformen . . . . . . . . . . . . . . . . 555700

a) Monistische Struktur . . . . . . . . . . . . . . . . 556700

b) Dualistische Struktur . . . . . . . . . . . . . . . . . . $557 \quad 700$

5. Arbeitnehmerbeteiligung . . . . . . . . . . . 558700

6. Buchführung, Bilanzierung, Steuern, Insolvenz. . . . . . 559701

XI. Betriebsaufspaltung . . . . . . . . . . . . . . . . . . . . . 560701

1. Vorbemerkung und Erscheinungsformen . . . . . . . . 560701

a) Vorbemerkung . . . . . . . . . . . . . . . . . . . . . 560701

b) Erscheinungsformen . . . . . . . . . . . . . . . . . . 563702

aa) Echte Betriebsaufspaltung . . . . . . . . . . . 563702

bb) Unechte Betriebsaufspaltung . . . . . . . . . . . . 564703

cc) Umgekehrte Betriebsaufspaltung . . . . . . . . . . 565703

dd) Kapitalistische Betriebsaufspaltung . . . . . . . . . 566703

ee) Mitunternehmerische Betriebsaufspaltung . . . . $567 \quad 703$

2. Gestaltungsgrundsätze . . . . . . . . . . . . . . . . . . 568703

a) Nutzungsüberlassungsvertrag . . . . . . . . . . . . . . 568703

aa) Höhe des Nutzungsentgelts . . . . . . . . . . . . . 569703

bb) Vertragsdauer. . . . . . . . . . . . . . . . . . . 570704

b) Verzahnung der Gesellschaftsverträge ... . . . . . 571704

\section{Vertragsabschluss}

I. Formfragen, Vertretung . . . . . . . . . . . . . . . . . . 572705

II. Registrierung . . . . . . . . . . . . . . . . . . . . . . . . . . 573705

\section{Vertragsdurchführung}

\section{Anforderung von Beiträgen, speziell Geltendmachung}

von Einlagen . . . . . . . . . . . . . . . . . . . . . . . . . 574707

1. Zuständigkeit . . . . . . . . . . . . . . . . . . . . 574707

2. Verfahren . . . . . . . . . . . . . . . . . . . . 575708

a) Personengesellschaften . . . . . . . . . . . . . . 575708

b) $\mathrm{GmbH} \ldots \ldots \ldots \ldots$. . . . . . . . . . . . . . . $576 \quad 708$

c) Einberufung Gesellschafterversammlung . . . . . . $577 \quad 708$

3. Formulierungsbeispiele. . . . . . . . . . . . . . . . 578708

a) Beschluss der Gesellschafterversammlung . . . . . . . $578 \quad 708$

b) Anforderungsschreiben gegenüber dem Gesellschafter $579 \quad 709$ 
II. Jahresabschluss und Ergebnisverwendung, Prüfung, Feststellung . . . . . . . . . . . . . . . . . . . . 580 709

1. Zuständigkeit . . . . . . . . . . . . . . . . 580709

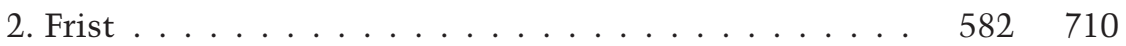

3. Prüfung . . . . . . . . . . . . . . . 583710

4. Verfahren bei Personenhandelsgesellschaften und GmbH $\quad 584 \quad 711$

III. Offenlegungspflichten . . . . . . . . . . . . . . . . 585711

1. Jahresabschlussbezogene Offenlegungspflichten . . . . 585711

a) Betroffene Gesellschaften . . . . . . . . . . . . . . 585711

b) Umfang der Offenlegungspflicht . . . . . . . . . . . . . 586711

aa) Kleine Gesellschaften . . . . . . . . . . . . . . 587711

bb) Mittelgroße Kapitalgesellschaften . . . . . . . . $588 \quad 712$

cc) Große Gesellschaften . . . . . . . . . . . . . . . . . 589712

dd) Sanktion . . . . . . . . . . . . . . . . . . . . 590712

2. Gesellschafterliste . . . . . . . . . . . . . 591712

a) Keine jährliche Gesellschafterliste . . . . . . . . . 591712

b) Ad-hoc-Einreichung . . . . . . . . . . . . . . . . 592712

IV. Ordentliche Gesellschafterversammlung . . . . . . . 593713

1. Gegenstand . . . . . . . . . . . . . . . . . . 593713

2. Vorbereitung . . . . . . . . . . . . . . . . . . . . . 594713

3. Durchführung . . . . . . . . . . . . . . . . . . . 595714

4. Formulierungsbeispiel Einladungsschreiben . . . . . 596714

V. Außerordentliche Gesellschafterversammlung und Gesellschafterversammlung auf Verlangen einer Minderheit $\quad 597 \quad 715$

1. Außerordentliche Gesellschafterversammlung . . . . . $597 \quad 715$

a) Erfordernis . . . . . . . . . . . . . . . . . . . . $597 \quad 715$

b) Tagesordnung . . . . . . . . . . . . . . . . . . . . . . 598716

c) Vorbereitung, Durchführung . . . . . . . . . . . . . . 599716

2. Gesellschafterversammlung auf Minderheitenverlangen $600 \quad 716$

a) Grundsätze . . . . . . . . . . . . . . . . . . . . 600716

b) Formulierungsbeispiel Einberufungsverlangen . . . $601 \quad 716$

c) Behandlung durch die Geschäftsführung/den Vorstand $602 \quad 717$

VI. Krisenszenario: Kündigung eines GesellschafterGeschäftsführers . . . . . . . . . . . . . . . . 603718

1. Betroffene Rechtsverhältnisse . . . . . . . . . . . . . 603718

a) Bei der GmbH. . . . . . . . . . . . . . . . . . . 603718

b) Bei Personengesellschaften . . . . . . . . . . . . . . . 604718

2. Gesellschafterversammlung . . . . . . . . . . . 605718 
3. Spezielles Durchführungsproblem bei der GmbH _. . $606 \quad 718$

4. Gewährung von Gehör . . . . . . . . . . . . . . . . 607719

VII. Wirtschaftliche Krisenszenarien . . . . . . . . . . . . 608719

1. Einfache „Unterbilanz" bei der GmbH . . . . . . . . . 608719

a) Feststellung . . . . . . . . . . . . . . . . . . . . . . . . 608719

b) Folge . . . . . . . . . . . . . . . . . . . . . . . . . . 609719

c) Vermeidung von Folgen . . . . . . . . . . . . . . . . 610719

2. Kapitalverlust von $1 / 2 \ldots \ldots \ldots$. . . . . . . . . . . . 611719

3. Insolvenzreife . . . . . . . . . . . . . . . . . . . . . 612720

Teil 5

Vertragsgestaltung und Steuern

(Meven)

\section{Einführung}

I. Bedeutung der Steuerfragen bei Austauschverträgen . . $\quad 1721$

II. Bedeutung der Steuerfragen bei Gesellschaftsverträgen $\quad 6 \quad 722$

III. Internationales Recht . . . . . . . . . . . . . . . . . 9723

1. Steuerliches Kollisionsrecht/anwendbares Recht . . . 99723

a) Umsatzsteuer . . . . . . . . . . . . . . . . . . . . . . 10723

b) Grunderwerbsteuer . . . . . . . . . . . . . . . . . . . . 11723

c) Zölle und Verbrauchsteuern . . . . . . . . . . . . . $12 \quad 724$

d) Ertragsteuern . . . . . . . . . . . . . . . . . . . . . 13724

2. Steuerfragen in ausländischen Rechtssystemen . . . . 14725

\section{Vertragsplanung}

I. Priorität der steuerrechtlichen Aspekte für verschiedene Gestaltungsmöglichkeiten . . . . . . . . . . . . . 19727

II. Zusammenarbeit zwischen Rechtsanwälten und Steuerberatern . . . . . . . . . . . . . . . . . $20 \quad 727$

III. Einholung verbindlicher Auskünfte bei den Finanzbehörden . . . . . . . . . . . . . . . . 21728

1. Zusage nach Betriebsprüfung . . . . . . . . . . . $23 \quad 729$

2. Lohnsteuerauskunft/Zollauskunft . . . . . . . . . . . 24729

3. Verbindliche Auskunft . . . . . . . . . . . . . . . 25729 
IV. Zusammenarbeit mit ausländischen Anwälten und

Steuerberatern

Rz. Seite

\section{Austauschverträge}

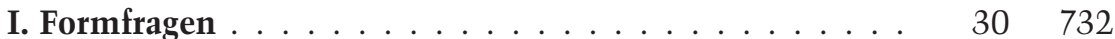

II. Vertragssprache . . . . . . . . . . . . . . . . . . . . 32733

III. Steuercheckliste und Kommentar . . . . . . . . . . . 33733

1. Checkliste Austauschverträge . . . . . . . . . . . . 33733

2. Kommentar Checkliste Austauschverträge . . . . . . $34 \quad 734$

a) Umsatzsteuer . . . . . . . . . . . . . . . . . . . . . . . . 34734

aa) Ausgangsumsatz . . . . . . . . . . . . . . . . . 35734

bb) Vorsteuerabzug. . . . . . . . . . . . . . . . . . . . 41736

cc) Steuerentstehung . . . . . . . . . . . . . 45738

dd) Abtretung „Vorsteuerguthaben" . . . . . . . . . 47739

b) Grunderwerbsteuer/Verkehrsteuern . . . . . . . . . . 49740

aa) Steuergegenstand . . . . . . . . . . . . . . 50740

bb) Bemessungsgrundlage. . . . . . . . . . . . . . $52 \quad 741$

cc) Steuerschuldner . . . . . . . . . . . . . . . 53741

c) Zölle und Verbrauchsteuern . . . . . . . . . . . . . . $54 \quad 542$

aa) Verbrauchsteuern . . . . . . . . . . . . . . . 55742

bb) Zölle und Einfuhrumsatzsteuer . . . . . . . . . . . 56742

d) Ertragsteuern . . . . . . . . . . . . . . . . . . . . . $57 \quad 743$

IV. Einzelprobleme . . . . . . . . . . . . . . . . . . . . 61745

1. Rückbeziehung . . . . . . . . . . . . . . . . . $61 \quad 745$

2. Haftungsfragen . . . . . . . . . . . . . . . 63746

3. Steuerklauseln . . . . . . . . . . . . . . . . . 64746

a) Umsatzsteuer . . . . . . . . . . . . . . . . . . . . . . $66 \quad 747$

b) Grunderwerbsteuer/Verkehrsteuern . . . . . . . . . . $67 \quad 674$

c) Zölle und Verbrauchsteuern . . . . . . . . . . . . . . . 68748

d) Ertragsteuern . . . . . . . . . . . . . . . . . . . . . 69748

V. Durchführung . . . . . . . . . . . . . . . . . . . . 71748

1. Steuererklärungs- und Meldepflichten/Fristen . . . . . $71 \quad 748$

a) Umsatzsteuer . . . . . . . . . . . . . . . . . . . . . . . 72749

b) Grunderwerbsteuer . . . . . . . . . . . . . . . $75 \quad 750$

c) Zölle und Verbrauchsteuern . . . . . . . . . . . . . . . $76 \quad 750$

d) Ertragsteuern . . . . . . . . . . . . . . . . . . $78 \quad 751$

2. Besondere Meldepflichten . . . . . . . . . . . . 79751 
3. Einbehaltungspflichten . . . . . . . . . . . . . . $80 \quad 751$

a) Umsatzsteuer . . . . . . . . . . . . . . . . . . . . . . 80751

b) Ertragsteuern . . . . . . . . . . . . . . . . . . . 81752

\section{Gesellschaftsrechtliche Verträge}

I. Planung . . . . . . . . . . . . . . . . . . . . . . . . . . . . . $82 \quad 754$

1. Steuerrechtlicher Systemunterschied . . . . . . . . . . 83754

a) Mitunternehmerschaft . . . . . . . . . . . . . . . . . 84754

b) Körperschaften . . . . . . . . . . . . . . . . . . . 88756

c) Ausländische Gesellschaftsformen . . . . . . . . . . . . 89756

d) Steuerrechtliche Konsequenzen . . . . . . . . . . . 90757

e) Gesetzesänderungen . . . . . . . . . . . . . . . . . . . . . 94759

f) Belastungsvergleich. . . . . . . . . . . . . . . . $97 \quad 759$

2. Wahl der Gesellschaftsform . . . . . . . . . . . . . 100761

a) Checkliste Gesellschaftsform . . . . . . . . . . . . . 101761

b) Kommentar Checkliste Gesellschaftsform Personengesellschaft. . . . . . . . . . . . . . . . 102761

a) Gewinn- und Verlustausgleich . . . . . . . . . 102761

bb) Entnahmen................. 103762

cc) Gesellschaftervergütungen/Pensionsrückstellungen . . . . . . . . . . . . . . . . . 104762

dd) Verdeckte Gewinnausschüttungen . . . . . . . . 105762

ee) Zeitpunkt der Ergebniszurechnung . . . . . . . . 106763

ff) Beteiligung ausländischer Gesellschafter . . . $107 \quad 763$

gg) Finanzierung. . . . . . . . . . . . . . 108763

hh) Umfang Betriebsvermögen/Transfer/Nutzungsüberlassung. . . . . . . . . . . . . . . . . . . . . 109764

ii) Gewinn-/Verlustzurechnung . . . . . . . . . . 111765

ij) Grunderwerbsteuer . . . . . . . . . . . . . 112765

kk) Erbschaftsteuer . . . . . . . . . . . . . . . 113765

11) Gewerbesteuer. . . . . . . . . . . . . . . 114766

mm) Behandlung der Anschaffungskosten . . . . . . . 115766

nn) Steuerrechtliche Haftung . . . . . . . . . . 116767

c) Kommentar Checkliste Gesellschaftsform Kapitalgesellschaft. . . . . . . . . . . . . . . . . . . 117767

aa) Gewinn-/Verlustausgleich . . . . . . . . . . $117 \quad 767$

bb) Entnahme . . . . . . . . . . . . . . 118767

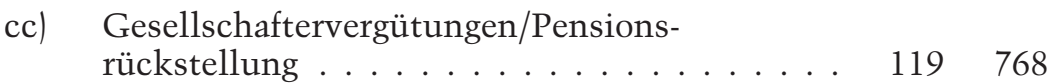


dd) Verdeckte Gewinnausschüttungen $\quad$ Rz. Seite

ee) Zeitpunkt der Ergebniszurechnung . . . . . . . $122 \quad 769$

ff) Beteiligung ausländischer Gesellschafter . . . . $123 \quad 770$

gg) Finanzierung . . . . . . . . . . . . . . . . 124770

hh) Umfang Betriebsvermögen/Transfer/Nutzungsüberlassung . . . . . . . . . . . . . . . $125 \quad 771$

ii) Steueranrechnung . . . . . . . . . . . . . 126771

ij) Grunderwerbsteuer. . . . . . . . . . . . . . . . $127 \quad 772$

kk) Erbschaftsteuer . . . . . . . . . . . . . 128772

11) Gewerbesteuer . . . . . . . . . . . . . . . . 129773

mm) Behandlung der Anschaffungskosten . . . . . . 130773

nn) Steuerrechtliche Haftung . . . . . . . . . . . . 131773

II. Gründung . . . . . . . . . . . . . . . . . . . . . . . . . . 132773

1. Checkliste Gesellschaftsvertrag. . . . . . . . . . . . . . 133774

2. Kommentar Checkliste Gesellschaftsvertrag . . . . . . 135774

a) Personengesellschaft. . . . . . . . . . . . . . . . . 135774

aa) Kapitalkonten/sonstige Gesellschafterkonten . 135774

bb) Gewinnermittlung/Gesellschaftervergütungen $136 \quad 775$

cc) Gewinn-/Verlustzurechnung . . . . . . . . . . 138776

dd) Regelstatut KG . . . . . . . . . . . . . . . . . 139776

ee) Sacheinlagen . . . . . . . . . . . . . . . . . . . 140777

ff) Sonderbetriebsvermögen . . . . . . . . . . . . 142777

gg) Geschäftsjahr . . . . . . . . . . . . . . . . 143777

hh) Gründungskosten. . . . . . . . . . . . . . . 145778

ii) Beginn der steuerlichen Existenz . . . . . . . . . 146778

b) Kapitalgesellschaft . . . . . . . . . . . . . . . . . . . . . $147 \quad 779$

aa) Wettbewerbsverbot. . . . . . . . . . . . 147779

bb) Sacheinlagen . . . . . . . . . . . . . . 148779

cc) vGA-Klausel. . . . . . . . . . . . . . . . . . . 149779

dd) Dienstleistungsverpflichtungen/Gesellschaftervergütungen . . . . . . . . . . . . . 150779

ee) Gewinnermittlung, Unterschied Handelsbilanz/Steuerbilanz . . . . . . . . . . . . . . 151780

ff) Gewinnverteilung . . . . . . . . . . . $152 \quad 780$

gg) Geschäftsjahr . . . . . . . . . . . . . . . . 153780

hh) Gründungskosten. . . . . . . . . . . . . . . 154780

ii) Beginn der steuerlichen Existenz . . . . . . . . . 155780

III. Durchführung . . . . . . . . . . . . . . . . . . . . . . 156781

1. Allgemeine Meldepflichten . . . . . . . . . . . . 156781 
a) Anmeldung . . . . . . . . . . . . . . . . . . . . . . . 156781

b) Umsatzsteuer . . . . . . . . . . . . . . . . . . . . . . . . . . 158782

c) Verkehrsteuern . . . . . . . . . . . . . . . . . . . . . . . 159782

d) Ertragsteuern (Gewerbe-, Einkommen-, Körperschaftsteuer . . . . . . . . . . . . . . . . . . . . . . . 160782

e) Lohnsteuer/Sozialversicherung . . . . . . . . . . . . 162783

f) Verbrauchsteuern/Zölle . . . . . . . . . . . . . . . . . . 163783

g) Kapitalertragsteuer . . . . . . . . . . . . . . . . . . . . . 164783

2. Verträge der laufenden Geschäftstätigkeit . . . . . . . . 165783

IV. Umstrukturierung. . . . . . . . . . . . . . . . . . . . . . . 166784

1. Gesellschafterwechsel . . . . . . . . . . . . . . . . 167784

a) Personengesellschaft. . . . . . . . . . . . . . . . . . . $167 \quad 784$

b) Kapitalgesellschaft . . . . . . . . . . . . . . . . . . . . . 170785

2. Umwandlungen . . . . . . . . . . . . . . . . . . . . . . . 172786

a) Gesamtrechtsnachfolge . . . . . . . . . . . . . . . $173 \quad 787$

aa) Verschmelzung. . . . . . . . . . . . . . . . . . . 173787

bb) Spaltung. . . . . . . . . . . . . . . . . . . . . . . . $176 \quad 788$

cc) Formwechsel . . . . . . . . . . . . . . . . . . . . . 179789

b) Einzelrechtsnachfolge . . . . . . . . . . . . . . . . 180789

aa) Einbringung/Sacheinlage . . . . . . . . . . . . . . 180789

bb) Verdeckte Sacheinlage . . . . . . . . . . . . . . . 182790

cc) Anteilstausch . . . . . . . . . . . . . . . . . 182a 791

3. Weitere Umwandlungsmöglichkeiten . . . . . . . . . 183791

a) Tausch/Einzelrechtsübertragung. . . . . . . . . . . . . 184791

b) Realteilung . . . . . . . . . . . . . . . . . . . . . . . 186791

c) Anwachsung . . . . . . . . . . . . . . . . . . . . . . 187792

d) Betriebsaufspaltung . . . . . . . . . . . . . . . . . . . 189793

4. Steuerrechtlich motivierte Umwandlungen . . . . . . . 191793

V. Beendigung . . . . . . . . . . . . . . . . . . . . . . . . . . . 194794

1. Personengesellschaft . . . . . . . . . . . . . . . . . 195794

a) Veräußerung . . . . . . . . . . . . . . . . . . . . . . . 195794

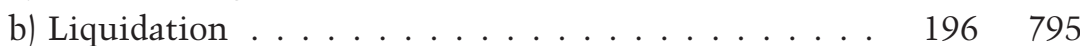

2. Kapitalgesellschaft . . . . . . . . . . . . . . . . . 197796

a) Veräußerung . . . . . . . . . . . . . . . . . . . . . 197796

b) Liquidation . . . . . . . . . . . . . . . . . . . 198796 


\section{Steuerrechtliches Vertrags-Controlling}

I. Begriff . . . . . . . . . . . . . . . . . . . . . . . . . . 200797

II. Steuerplanung . . . . . . . . . . . . . . . . . . . . . . 201797

III. Dokumentation . . . . . . . . . . . . . . . . . . . . . . 202798

IV. Erklärungs- und Meldepflichten ．. . . . . . . . . . . 204799

V. Verbesserung von Checklisten . . . . . . . . . . . . . 205799

Teil 6

Vertragsenglisch

(Pischel)

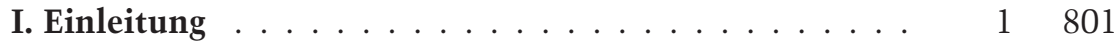

II. Grundlagen . . . . . . . . . . . . . . . . . . . . . . . . 58

1. Case Law und Codified Law . . . . . . . . . . . . . 5803

a) Rechtsprechung und Gesetz . . . . . . . . . . . . $5 \quad 503$

b) Spielraum der Interpretation . . . . . . . . . . . . . 6804

c) Consideration . . . . . . . . . . . . . . . . . . . . 10806

d) Abstraktionsprinzip . . . . . . . . . . . . . . . . $11 \quad 807$

2. Verhandlungen mit Briten . . . . . . . . . . . . . 12807

3. Allgemeine Grundsätze der Vertragsgestaltung auf Englisch . . . . . . . . . . . . . . . . . . . . . 15809

a) Vermeidung von allgemeinen Undeutlichkeiten . . . 15809

b) Begriff und rechtliche Anknüpfung . . . . . . . . . 19810

c) Punkt und Komma . . . . . . . . . . . . . . . . . . . . 21812

4. Groß- und Kleinschreibung . . . . . . . . . . . . . . . $22 \quad 813$

a) Definitionen . . . . . . . . . . . . . . . . . . . 23813

b) Weitere Ausnahmen . . . . . . . . . . . . . . . . 25814

5. Normalschrift, Kursives und Fettdruck . . . . . . . . . 27814

III. Aufbau englischsprachiger Verträge . . . . . . . . . . . $28 \quad 814$

IV. Einzelne Begriffe . . . . . . . . . . . . . . . . . . . . $33 \quad 817$

1. Verpflichtung und Berechtigung . . . . . . . . . . $33 \quad 817$

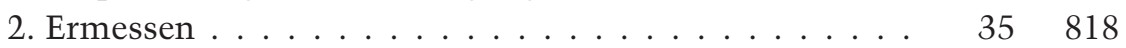

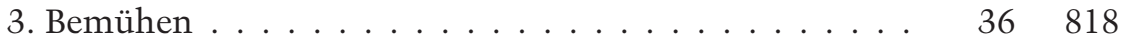

4. Zustimmungsvorbehalte . . . . . . . . . . . . . . . $38 \quad 819$

5. Regelungen im Kontext der Verträge . . . . . . . . . . 39820

6. Bedingung, Ausnahme, Vermutung, negative Formulie- $42 \quad 821$ rung und Beweislastverschiebung. . . . . . . . . . $42 \quad 821$ 
a) Vermutungsregeln . . . . . . . . . . . . . . . $43 \quad 821$

b) Bedingungen . . . . . . . . . . . . . . . . . . . 44821

c) Ausnahmen . . . . . . . . . . . . . . . . . . . . 49822

d) Negative Formulierungen . . . . . . . . . . . . . . . . $50 \quad 823$

V. Einzelne Formulierungen in der Vertragsgestaltung . . . $51 \quad 823$

1. Leistungszeit . . . . . . . . . . . . . . . . . . . . . $51 \quad 823$

a) Effective Date, Signing und Closing . . . . . . . . . . $51 \quad 823$

b) Prompt and without undue delay vs. Time of Essence $\quad 52 \quad 824$

c) Klarheit der Fristbestimmung . . . . . . . . . . . . . . . 53824

2. Erfüllungsort - Ship and Deliver . . . . . . . . . . . . . . $56 \quad 525$

3. Representation, Warranties and Guarantees . . . . . . . $57 \quad 825$

a) Representation . . . . . . . . . . . . . . . . $58 \quad 826$

b) Warranty . . . . . . . . . . . . . . . . . . . . . . . . . 59826

c) Guarantee . . . . . . . . . . . . . . . . . . . . $61 \quad 827$

4. Liability, Damages and Indemnification . . . . . . . . 62827

a) Liability . . . . . . . . . . . . . . . . . . . . . . . . . . . . $63 \quad 827$

b) Damages . . . . . . . . . . . . . . . . . . . . . . . . . . 64828

c) Indemnification . . . . . . . . . . . . . . . . . $66 \quad 629$

5. Corporate Guarantee, Recourse and Joint Debtors . . . . $67 \quad 67829$

6. Termination . . . . . . . . . . . . . . . . . . 69830

7. Zustellung und Empfang . . . . . . . . . . . . . . . . . $71 \quad 831$

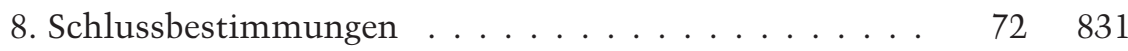

Teil 7

Außergerichtliche Konfliktbeilegung Institutionen und Verfahren im In- und Ausland

(Ponschab)

I. Wesen und Bedeutung von Außergerichtlicher Konfliktbeilegung (AKB) . . . . . . . . . . . . . . . . 1833

1. Konfliktentscheidungen durch Dritte (heteronome Konfliktbeilegung) . . . . . . . . . . . . . . . . 2834

2. Konfliktlösungen durch die Parteien (autonome Konfliktbeilegung) . . . . . . . . . . . . . . . . . 3834

3. Obligatorische Streitschlichtung . . . . . . . . 7836

II. Entwicklung der Institutionen der Außergerichtlichen

Konfliktbeilegung . . . . . . . . . . . . . . . 12840

1. Entwicklung in der Bundesrepublik Deutschland . . . . $12 \quad 840$

2. Entwicklung in den USA und anderen Ländern . . . . . $23 \quad 846$ 
III. Die Bedeutung von AKB beim Konfliktmanagement von Verträgen . . . . . . . . . . . . . . . . . . . . $30 \quad 850$

1. Die Stufen des Konfliktmanagements bei Verträgen . . . $30 \quad 850$

2. Vorteile von AKB . . . . . . . . . . . . . . . . 35851

a) Interessengerechte Lösungen . . . . . . . . . . . . . $36 \quad$. . 851

b) Erhaltung guter Geschäftsbeziehungen . . . . . . . . . . $38 \quad 853$

c) Ersparnis von Zeit . . . . . . . . . . . . . . . . . . . . 39853

d) Ersparnis von Kosten . . . . . . . . . . . . . . . . $40 \quad 853$

e) Planungssicherheit . . . . . . . . . . . . . . . . . . 42855

f) Kontrolle über den Verhandlungsprozess . . . . . . . . 43855

g) Diskretion/Ausschluss der Öffentlichkeit . . . . . . . 44855

h) Besondere Sachkunde . . . . . . . . . . . . 45856

i) Informelle (nichtförmliche) Verfahrensweise . . . . . $46 \quad 856$

3. Ungeeignete Fälle . . . . . . . . . . . . . . . . . 47856

IV. Systematische Darstellung einzelner Verfahren der AKB $\quad 48 \quad 857$

1. Verhandlung . . . . . . . . . . . . . . . . . . . $50 \quad 859$

2. Moderation . . . . . . . . . . . . . . . . . . . . 51859

3. Mediation/Vermittlung. . . . . . . . . . . . . . $52 \quad 859$

a) Prinzipien des Mediationsverfahrens . . . . . . . . $53 \quad 860$

aa) Vertraulichkeit. . . . . . . . . . . . . . . $53 \quad 860$

bb) Freiwilligkeit . . . . . . . . . . . . . . . . . . $54 \quad 861$

cc) Eigenverantwortlichkeit . . . . . . . . . . . $55 \quad 861$

dd) Einvernehmliche Beilegung des Konflikts . . . . . $56 \quad 862$

b) Aufgaben und Pflichten des Mediators . . . . . . . . 57863

aa) Unabhängigkeit (Unparteilichkeit) . . . . . . . . $57 \quad 563$

bb) Neutralität . . . . . . . . . . . . . . . . . . . . . $58 \quad$. . . . . . 863

cc) Offenbarungspflichten . . . . . . . . . . . . . $59 \quad 564$

dd) Prüfungspflichten . . . . . . . . . . . . . . . . . . $60 \quad 864$

ee) Klärung der Abschlussvereinbarung . . . . . . . . 61864

ff) Verschwiegenheit ............... 62864

gg) Pflicht des Mediators zu Aus- und Fortbildung $(\S \S 5,6$ MedG) $\ldots \ldots \ldots \ldots$. . . . . . . . . . . . . . . $63 \quad \ldots 64$

4. Schlichtung . . . . . . . . . . . . . . . . . 64865

5. Neutraler Experte . . . . . . . . . . . . . . . . . . . 65865

6. Schiedsgutachten/Schiedsrichter . . . . . . . . . . $66 \quad 865$

7. Schiedsschlichtung (Med/Arb oder Arb/Med) . . . . . . . 67865

8. Spezielle Schiedsverfahren (Tailored Arbitration) . . . . $68 \quad 866$

9. Michigan Mediation . . . . . . . . . . . . . . . 69866

10. Last-Offer-Arbitration . . . . . . . . . . . . 70866 
11. High-Low-Arbitration ．. . . . . . . . . . . . . . 71866

12. Miniverfahren (Mini-Trial) . . . . . . . . . . . . . . . . . 72867

13. Adjudikation . . . . . . . . . . . . . . . . . . . . . 73867

Teil 8

Verhandeln in Brüssel

(Williamson)

1 Einleitung $\ldots \ldots \ldots \ldots \ldots \quad 1 \quad 869$

2 Besonderheiten der Interessenvertretung und des Verhandelns auf EU-Ebene .... . $\quad 7 \quad 871$

3 Verhandeln mit der Europäischen Kommission in ihrer Funktion als Vollzugsbehörde

I. Allgemeines _ . . . . . . . . . . . . . . . . . . . . . . . . . $12 \quad 873$

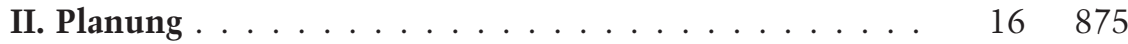

1. Problemidentifizierung . . . . . . . . . . . . . . . $16 \quad 275$

a) Positionsbestimmung . . . . . . . . . . . . . . $16 \quad 875$

aa) An einzelne Unternehmen gerichtete Kommis-

sionsentscheidungen . . . . . . . . . . . . $16 \quad 875$

bb) Beschwerderecht. . . . . . . . . . . . . . . . $18 \quad 875$

cc) Problembewusstsein und -identifizierung . . . . . 19876

b) Exkurs EU-Kartellrecht . . . . . . . . . . . . . . . . 21876

aa) Bedeutung des Kartellrechts . . . . . . . . . . . . 21876

bb) Dezentralisierung . . . . . . . . . . . . . . . $26 \quad 878$

cc) Ermittlungs- und Nachprüfungsbefugnisse der

Kommission . . . . . . . . . . . . . . . . . . $30 \quad 879$

dd) Anordnungsbefugnisse der Kommission . . . . . . $37 \quad 880$

ee) Reaktionsmöglichkeiten . . . . . . . . . . . . . $42 \quad 882$

(1) Kronzeugenprogramm . . . . . . . . . . . . . . $42 \quad 882$

(2) Vergleichsverfahren . . . . . . . . . . . . . . 45888

(3) Beschwerderecht des Konkurrenten. . . . . . . 53886

c) Exkurs Fusionskontrolle . . . . . . . . . . . . . . . . 61888

aa) Rechtlicher Rahmen . . . . . . . . . . . . . $61 \quad 888$

bb) Zusammenschluss von gemeinschaftsweiter

Bedeutung . . . . . . . . . . . . . . 65889

cc) Erhebliche Behinderung wirksamen Wettbewerbs 68890 
dd) Anmeldeverfahren . . . . . . . . . . . . . . . . . $70 \quad 891$

ee) Prüfungsverfahren . . . . . . . . . . . . . . . . . $73 \quad 892$

ff) Beteiligung Dritter . . . . . . . . . . . . . . . 75892

gg) Checkliste: Fusionskontrolle . . . . . . . . . . $76 \quad 893$

d) Exkurs Recht der staatlichen Beihilfen . . . . . . . . . 77893

aa) Begriff "staatliche Beihilfe" . . . . . . . . . . 79894

bb) Anmeldepflicht von staatlichen Beihilfen . . . . $82 \quad 895$

cc) Rolle der betroffenen Unternehmen im Verfahren $\quad 85896$

dd) Checkliste: Beihilfeverfahren . . . . . . . . . . 86897

e) Exkurs Grundfreiheiten . . . . . . . . . . . . . . . . . 87897

2. Beauftragung eines Experten . . . . . . . . . . . . . $90 \quad 898$

a) Erfahrung im Umgang mit der Kommission . . . . . . 91898

b) Kontakte zu Unternehmen und Verbänden . . . . . . 94899

c) Fremdsprachenkenntnisse . . . . . . . . . . . . . . 95899

3. Zuständige Abteilung innerhalb der Kommission . . . . 96900

4. Checkliste . . . . . . . . . . . . . . . . . . 102901

III. Durchführung . . . . . . . . . . . . . . . . . . . . . . . . 103902

1. Kontaktaufnahme . . . . . . . . . . . . . . . . . . . . . . . . . 103902

2. Informelles Vorgespräch . . . . . . . . . . . . . . . . 106903

a) Besetzung der Delegation . . . . . . . . . . . . . . . . . . . . . . . . . 108903

b) Briefing . . . . . . . . . . . . . . . . . . . . . . . . . . . . . . 109904

3. Einleitung des Verfahrens . . . . . . . . . . . . . . . . 112904

4. Die offizielle Anhörung . . . . . . . . . . . . . . . . 118906

5. Checkliste . . . . . . . . . . . . . . . . . . 121906

IV. Strategiekontrolle . . . . . . . . . . . . . . . . . . . . 122907

\section{Verhandeln mit den europäischen Institutionen im Gesetzgebungsverfahren}

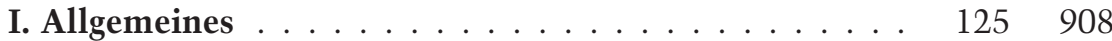

1. Das Gesetzgebungsverfahren … . . . . . . . . . . . . 128909

2. Die Kommission im Gesetzgebungsverfahren . . . . . 131910

3. Der Rat der Europäischen Union . . . . . . . . . . . . 133910

4. Das Europäische Parlament . . . . . . . . . . . . . . . . 135911

a) Selbstverständnis des Parlaments . . . . . . . . . . . 136912

b) Organisation . . . . . . . . . . . . . . . . . . . . . 137912

5. Der Wirtschafts- und Sozialausschuss . . . . . . . . . . 139913

6. Der Ausschuss der Regionen . . . . . . . . . . . . . . . 140913 
II. Planung . . . . . . . . . . . . . . . . . . . . . . . . . . . . . . 1419

1. Monitoring- und Informationsservice . . . . . . . . . 141913

2. Kontaktaufnahme mit betroffenen Wirtschaftsverbänden, Unternehmen und anderen privaten

Organisationen ...................... 145914

III. Durchführung . . . . . . . . . . . . . . . . . . . . . . . . 1489

1. Kontaktaufnahme mit der Kommission . . . . . . . . . . 1489915

2. Kontaktaufnahme zu Europäischem Parlament und Parlamentariern . . . . . . . . . . . . . . . . 151916

a) Besonderheiten bei der Kontaktaufnahme . . . . . . 155917

b) Treffen mit einem Parlamentarier . . . . . . . . . . . . 158918

3. Kontakt mit Rat und Mitgliedstaaten . . . . . . . . . . 160919

4. Zeitfaktor. . . . . . . . . . . . . . . . . . . . . 161919

5. Checkliste . . . . . . . . . . . . . . . . . . . 164920

IV. Strategiekontrolle . . . . . . . . . . . . . . . . . . 165920

5 Verträge mit den europäischen

Institutionen ........... $166 \quad 922$

6 Schlussfolgerungen $\ldots \ldots \ldots \quad 170 \quad 923$

7 Überblick

I. Die Institutionen der EU . . . . . . . . . . . . . . . . . . 173924

II. Europäische Kommission: Untergeordnete Dienste . . $174 \quad 924$

III. Europäisches Parlament: Ausschüsse ． . . . . . . . . . 176926

IV. Ordentliches Gesetzgebungsverfahren, Art. 294 AEUV . $177 \quad 927$

Teil 9

Verhandeln im Ausland

9.1

Verhandeln in den USA

(Kochinke)

1 Einführung: A Deal is Not a Deal . . $\quad 1 \quad 929$ 


\section{Vertragsmanagement}

I. Vertragsplanung . . . . . . . . . . . . . . . . . . . . . . . . . 8939

1. Bestehende Verträge als Hindernis . . . . . . . . . . . . 99933

2. Überlegungen zur fremden Wirtschaftskultur . . . . . . 10933

3. Einschaltung des US-Korrespondenzanwalts . . . . . . 15935

4. Informationsbeschaffung . . . . . . . . . . . . . . . 19937

5. Vorvertragliche Haftungsrisiken und Präventivmaßnahmen .................... 23938

a) Geheimhaltung . . . . . . . . . . . . . . . . . . . . 24938

b) Geistiges Eigentum . . . . . . . . . . . . . . . . . 26938

c) Verwertungsverbote . . . . . . . . . . . . . . . 28939

d) Planung für Fehlschlag - Default . . . . . . . . . . . $30 \quad 940$

e) Vorbereitende Sicherung von Rechten . . . . . . . . 32940

f) Klarstellung des Leistungserbringers . . . . . . . . . 35941

II. Vertragsdesign . . . . . . . . . . . . . . . . . . . . . . . . . 379

1. Struktur. . . . . . . . . . . . . . . . . . . . . . 3894

2. Bezeichnung der Vertragsparteien . . . . . . . . . . . . 43943

3. Schriftform - Statute of Frauds . . . . . . . . . . . . . 47943

4. Beglaubigung, Beurkundung, Besiegelung, Beeidigung. . $\quad 51944$

5. Erläuterungen (Defined Terms), Großschrift . . . . . . 55946

6. Unverzichtbar: Das Synallagma mit Leistungsaustausch $\quad 57946$

7. Terminologie. . . . . . . . . . . . . . . . . . 58947

8. Klarheit der Vertragssprache . . . . . . . . . . . . . . . 59947

9. Probleme bei Abbruch der Verhandlungen . . . . . . . 62949

a) Szenario: Vertrag schriftlich vereinbart und unterzeichnet . . . . . . . . . . . . . . . 63949

b) Szenario: Ergebnisse schriftlich festgehalten, doch nicht in einem Text . . . . . . . . . . . . . . . 64949

c) Szenario: Kein schriftlicher Vertrag, keine gegenseitigen Verpflichtungen vereinbart . . . . . . . . . . 68950

10. Wirkung von Vorvertragsvereinbarungen . . . . . . . 69950

a) Merger Clause - Saubere Entsorgung . . . . . . . . $70 \quad 950$

b) Bestätigung des Abbruches . . . . . . . . . . . . . . $72 \quad 952$

c) Verhandlungspause . . . . . . . . . . . . . . . . 73952

III. Vertragsverhandlung . . . . . . . . . . . . . . . . . . . . . . $74 \quad 953$

1. Inhaltliche Voraussetzungen $\ldots \ldots \ldots$

a) Bargaining . . . . . . . . . . . . . . . . . . . . . . 74953

b) Gegenleistung . . . . . . . . . . . . . . . . . . . 75953

c) Keine Vertragsstrafe . . . . . . . . . . . . . . . . . . 76954 
2. Verhandlungsthemen . . . . . . . . . . . . . . . . 78955

3. Vergleichsverhandlungen . . . . . . . . . . . . . 80956

4. Vertragsänderung . . . . . . . . . . . . . . . . . 81956

5. Abschluss der Verhandlungen: Closing . . . . . . . . . 82957

6. Rolle des Rechtsanwalts . . . . . . . . . . . . . . . . . . 85958

7. Kosten des Rechtsanwalts . . . . . . . . . . . . . . . . . 89959

8. Psychologische Faktoren . . . . . . . . . . . . . . . . . 96961

9. Verhandlungsorganisation . . . . . . . . . . . . . . . . 100962

IV. Vertragsdurchführung . . . . . . . . . . . . . . . . . . 105963

1. Unterzeichnung . . . . . . . . . . . . . . . . . . . . . . 106963

2. Vertragserfüllung (hart am Wortlaut) . . . . . . . . . . . . 112965

3. Vertrag in der Krise . . . . . . . . . . . . . . . . . . 117966

a) Auslöser für Krise (schweigsam, dann bockig) . . . . . 117966

b) Krisenvorbeugung durch Vertragsaktualisierung . . . 120967

c) Lethargie. . . . . . . . . . . . . . . . . . . . . . . . . . 123968

4. Vertrags- und Deliktsrecht . . . . . . . . . . . . . . . . 124968

5. Schiedsklausel verleiht Zuversicht . . . . . . . . . . . . . 125969

6. Öffentlichkeitsarbeit . . . . . . . . . . . . . . . . . . 126969

7. Gelassenheit bei Drohszenario . . . . . . . . . . . . . . . 127969

8. Stillhalteabkommen zur Deeskalation . . . . . . . . . . 136971

9. Diverse Reibungspunkte und Gelegenheiten . . . . . . . 137972

a) Firmierung . . . . . . . . . . . . . . . . . . . . . 138972

b) Ausstattung nach deutschem Geschmack . . . . . . . 139972

c) Ich liebe Las Vegas . . . . . . . . . . . . . . . . . . . . . 140973

d) Staatsangehörigkeit . . . . . . . . . . . . . . . . . . . . . 141973

e) Durchgriffshaftung . . . . . . . . . . . . . . . . . . . . . 142974

f) Business Plan . . . . . . . . . . . . . . . . . . . . . . . . 143974

g) Sprachprobleme . . . . . . . . . . . . . . . . . . 144975

h) Titel statt Geld . . . . . . . . . . . . . . . . . . . . . . 145976

V. Vertragscontrolling . . . . . . . . . . . . . . . . . . 146976

1. Vertragsdokumentation . . . . . . . . . . . . . . . . 1479977

2. Kontrolle der Vertragsdurchführung . . . . . . . . . . . 148978

3. Verbraucherverträge. . . . . . . . . . . . . . . . . . . 149979

3 Anhang $\ldots \ldots \ldots \ldots \ldots 152 \quad 980$ 


\section{2}

\section{Verhandeln in Russland}

(Schwarz)

\section{Einführung - Der ferne Nachbar}

Rz. Seite

I. Auf der Suche nach der russischen Seele . . . . . . . . . . 1983

1. Mythos und Realität . . . . . . . . . . . . . . . . . . . . . . 2984

2. Verhältnis von Russen zu Deutschen . . . . . . . . . . . . 3984

3. Zentrale und Provinz . . . . . . . . . . . . . . . . . . 4984

II. Zwischen Staatsmonopolkapitalismus und kontinentaleuropäischem Recht . . . . . . . . . . . . . . 5985

1. Ein Land auf der Suche nach den passenden Rahmenbedingungen ................... 5985

2. Das sozialistische Erbe lebt fort . . . . . . . . . . . 6986

3. Die turbulenten Jahre der Perestrojka und ihre rechtlichen Folgen . . . . . . . . . . . . . . . . 7987

4. Die Ära Putin . . . . . . . . . . . . . . . . . . . . . 8987

\section{Vertragsmanagement}

I. Vertragsplanung . . . . . . . . . . . . . . . . . . . 9 9990

1. Einschaltung des russischen Korrespondenzanwalts . . . 99990

a) Von Advokaten und Juristen . . . . . . . . . . . . . 10990

b) Internationale Kanzleien. . . . . . . . . . . . . . . . . . 14991

c) Russische Kanzleien . . . . . . . . . . . . . . . . . . 18992

2. Informationsbeschaffung . . . . . . . . . . . . . . . . . 19993

a) Zugang zu öffentlichen Registern _ . . . . . . . . . 19993

b) Umfang und Qualität der erhältlichen Informationen . $\quad 20993$

c) Schutz des öffentlichen Glaubens in staatliche Register $\quad 23993$

3. Vorvertragliche Haftungsrisiken und Präventivmaßnahmen . . . . . . . . . . . . . . . . . . . . . 24994

a) Geheimhaltung . . . . . . . . . . . . . . . . . . . . . . . 24994

b) Geistiges Eigentum . . . . . . . . . . . . . . . . . . . . . 26994

II. Vertragsdesign . . . . . . . . . . . . . . . . . . . . . . . . . 30995

1. Struktur - Form over Function . . . . . . . . . . . . . . . 30995

a) Die Wichtigkeit der geschriebenen Vereinbarung . . . 31996

b) Die Bedeutung der Vertragsform . . . . . . . . . . . . 32996

2. Schriftform . . . . . . . . . . . . . . . . . . 33997

a) Gesetzliche Schriftform . . . . . . . . . . . . . . . 33997 
b) Gewillkürte Schriftform . . . . . . . . . . . . . . . . 34997

3. Vertretungsrecht. . . . . . . . . . . . . . . . . . 35997

a) Gesetzliche Vertreter von juristischen Personen und Vertretungsnachweis . . . . . . . . . . . . . . 35997

b) Originäre Vertretungsmacht . . . . . . . . . . . . . . 38998

c) Stellvertretung, Vertreter ohne Vertretungsmacht, Anscheinsvollmacht. . . . . . . . . . . . . . . 40998

d) Zustimmung von Aufsichtsorganen, gesetzliche Organvorbehalte . . . . . . . . . . . . . . . . . 41999

e) Zustimmung von Behörden . . . . . . . . . . . . . . . 43999

f) Beurkundungs- und registrierungspflichtige Geschäfte $\quad 45 \quad 1000$

4. Vertragsaufbau . . . . . . . . . . . . . . . . 471001

5. Zwingendes Recht als Beschränkung der Parteiautonomie $\quad 481001$

a) Was nicht ausdrücklich erlaubt ist, erscheint (zunächst) erst einmal verboten . . . . . . . . . . . 481001

b) Russisches Devisenrecht . . . . . . . . . . . . . . 491002

6. Vertragstypenzwang, Gemischte Verträge, Atypische Verträge . . . . . . . . . . . . . . . . . . 501002

a) Im russischen ZGB geregelte Vertragstypen . . . . . . 501002

b) Behandlung von gemischten Verträgen und Verträgen sui generis . . . . . . . . . . . . . . . . . . . 511003

7. Wirkung von Vorvertragsvereinbarungen . . . . . . . 521003

III. Vertragsverhandlung . . . . . . . . . . . . . . . . . . . . 531003

1. Inhaltliche Voraussetzungen . . . . . . . . . . . . . 531003

a) Verhandlungssprache . . . . . . . . . . . . . . . . . . 531003

b) Dolmetscherdienste . . . . . . . . . . . . . . . . . . . . 541004

c) Zeitansatz . . . . . . . . . . . . . . . . . . . . . . 551005

2. Gesprächsthemen . . . . . . . . . . . . . . 561005

a) Klare Strukturierung der zu besprechenden Themen . $\quad 57 \quad 1006$

b) Abgrenzung von Geschäftsthemen und juristischen

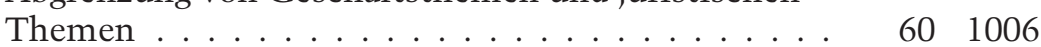

c) Verhandlungsprotokoll, Term Sheet . . . . . . . . . . 611006

3. Vertragsänderung . . . . . . . . . . . . . . . . . . 631007

a) Inhaltliche Einigung . . . . . . . . . . . . . . . . . 641007

b) Vertragliche Fassung der Vertragsänderungen . . . . . 651007

c) Rückwirkung von Änderungen . . . . . . . . . . . . . . $66 \quad 661007$

4. Abschluss der Verhandlungen (Closing) . . . . . . . . . 681008

5. Rolle des Rechtsanwalts . . . . . . . . . . . . . . . . . . 691009

6. Kosten des Rechtsanwalts . . . . . . . . . . . . . . 701009

7. Psychologische Faktoren . . . . . . . . . . . . . . . . 711010 
8. Mittelsmänner, Vermittler und andere Gestalten . . . 761011

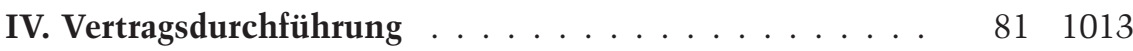

1. Unterzeichnung . . . . . . . . . . . . . . . . . . . . . . . 811013

2. Vertragserfüllung . . . . . . . . . . . . . . . . . 821013

3. Vertrag in der Krise . . . . . . . . . . . . . . . . . . . 841013

4. Vertrags- und Deliktsrecht . . . . . . . . . . . . . . . 891015

5. Schiedsklausel . . . . . . . . . . . . . . . . . . 901015

a) Übliche Schiedsklauseln und Schiedsgerichte . . . . . 911016

b) Vollstreckung von Schiedsurteilen in Russland . . . . 921017

V. Vertragscontrolling . . . . . . . . . . . . . . . . . 931017

1. Besondere Bedeutung im Rechtsverkehr mit Russland . $\quad 931017$

2. Vertragscontrolling beginnt beim richtigen Vertragsdokument ................... 941018

3. Nach dem Closing geht die Arbeit erst richtig los . . . 951018

4. Risiken erkennen und richtig adressieren . . . . . . . . 961019

5. Zentrales Archiv als Controlling-Tool . . . . . . . . . 971019

\section{Anhang}

I. Registrierungsbehörden ～. . . . . . . . . . . . . . . 991021

II. Ausländische und russische Wirtschaftsverbände . . . . 1001021

III. Sonstige nützliche Adressen . . . . . . . . . . . . . . . . 1011022

IV. Internetadressen . . . . . . . . . . . . . . . . . . . . . . 1021022

\section{3 \\ Verhandeln in China \\ (Pattloch)}

I. Kulturelle Besonderheiten . . . . . . . . . . . . . . . 11026

1. Gesellschaftspolitische Rahmenbedingungen in China . 11026

a) Die Stellung des Individuums in der chinesischen

Gesellschaft . . . . . . . . . . . . . . . 21027

b) Konfuzianismus und Herrschaft des Rechts . . . . . $\quad 51028$

c) Inländer und Ausländer . . . . . . . . . . . . . . . 81029

d) Die Betonung der hierarchischen Stellung in der

Gesellschaft ................... 91030

2. Streben nach Harmonie . . . . . . . . . . . . . . . 121031

3. Das chinesische Verständnis vom Vertrag . . . . . . . 151032 
4. Guanxi (Beziehungen)

a) Beziehungsnetzwerke als Ordnungsprinzip der chinesischen Gesellschaft . . . . . . . . . . . 181032

b) Das "Gehen durch die Hintertür" . . . . . . . . . . . . . . . 231034

c) Der Inhalt von Guanxi . . . . . . . . . . . . . . . . . . 241034

d) Guanxi und Vertragsverhandlungen . . . . . . . . . . . . . . 271035

5. Gesicht (Mianzi) und Vertragsverhandlungen . . . . . . . 281035

a) Die Bedeutung von Mianzi . . . . . . . . . . . . . . . . . . 291036

b) Gesicht wahren . . . . . . . . . . . . . . . . . . . 331037

c) Gesicht verlieren . . . . . . . . . . . . . . . . . . . . . . . . . . . 341037

d) Gesicht gewinnen . . . . . . . . . . . . . . . . 351038

e) Gesicht nehmen . . . . . . . . . . . . . . . . . . . . . . . . . . . . . . . . . . . . . . 1038

f) Gesicht geben . . . . . . . . . . . . . . . 371039

6. Nationalbewusstsein und Verhandlungsstil . . . . . . . 381039

II. Vertragsvorbereitungen . . . . . . . . . . . . . . . . . . 401040

1. Verhandlungs- und Vertragspartner . . . . . . . . . . . . . 411040

a) Der richtige Verhandlungspartner . . . . . . . . . . . . . 411040

b) Risiko des falschen Verhandlungspartners . . . . . . . 421041

c) Überprüfen des Vertragspartners . . . . . . . . . . . . . . . . . . . . . 431042

d) Weitere Verhandlungspartner. . . . . . . . . . . . . 451043

2. Das eigene Team . . . . . . . . . . . . . . . . 461043

a) Psychologisches Verhandlungsgleichgewicht . . . . . 471043

b) Rollenverteilung . . . . . . . . . . . . . . . . . . . . 481043

c) Hierarchie der Teammitglieder . . . . . . . . . . . . . 491044

d) Fachleute . . . . . . . . . . . . . . . . . . . . . . . . . . 501044

e) Assistenten und Kontaktpersonen . . . . . . . . . . . . . . . 511045

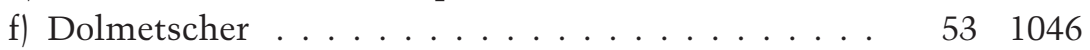

g) Rechtsanwälte . . . . . . . . . . . . . . . . . . . . . 591047

3. Ziele von Vertragsverhandlungen . . . . . . . . . . . . . 611047

a) Rechtlich und verhandlungstechnisch realistische
Zielsetzung . . . . . . . . . . . . 621048

b) Einplanen von Rückzugsräumen und sog. Dealbreaker $\quad 661049$

c) Flexibilität. . . . . . . . . . . . . . . . 681050

4. Logistik und Zeitplanung . . . . . . . . . . . . . 701050

III. Vertragsplanung . . . . . . . . . . . . . . . . . . . . . . 711051

1. Faktoren der Vertragsplanung . . . . . . . . . . . . . . 721051

a) Erfahrung des Vertragspartners . . . . . . . . . . . . . . . 721051

b) Eigene Verhandlungsposition . . . . . . . . . . . . . . . . . . . 731052

c) Konkurrenz . . . . . . . . . . . . . . . . . . 741052 
d) Einfluss der Behörden . . . . . . . . . . . . . . . . $75 \quad 1052$

2. Typische Stufen bis zum Vertragsschluss . . . . . . . $76 \quad 7052$

a) Kontaktaufnahme . . . . . . . . . . . . . . . 771052

b) Letter of Intent . . . . . . . . . . . . . . . . . . . . 781053

c) Behördliche Erfordernisse . . . . . . . . . . . . . . . 791054

d) Vertragsschluss . . . . . . . . . . . . . . . . . . . . . 811054

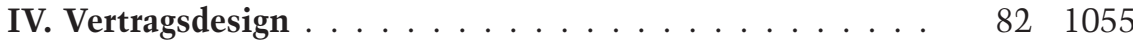

1. Musterverträge . . . . . . . . . . . . . . . . . . . . . . . . 831055

2. Drafting Prozess . . . . . . . . . . . . . . . . . . 841055

3. Rechtliche Besonderheiten . . . . . . . . . . . . 851056

a) Schiedsklauseln . . . . . . . . . . . . . . . 861056

b) Rechtswahl . . . . . . . . . . . . . . . . . . 881057

c) Behördliche Genehmigungen . . . . . . . . . . . . . 891057

d) Erfüllung von Forderungen . . . . . . . . . . . . . . 901057

e) Beweis des Zugangs von Erklärungen . . . . . . . . . . 911058

f) Vertragsstrafe und Schadensersatz . . . . . . . . . . . . 9 921058

g) Der Staat als Vertragspartner . . . . . . . . . . . . . . 931058

h) Erfüllbarkeit eigener Zusagen . . . . . . . . . . . . 941058

i) Geheimhaltungsvereinbarungen . . . . . . . . . . . . 951059

V. Vertragsverhandlungen . . . . . . . . . . . . . . . . . . 961059

1. Schematischer Verhandlungsverlauf . . . . . . . . . . 961059

2. Technischer Ablauf . . . . . . . . . . . . . . . 971060

a) Verhandlungsort; Pünktlichkeit . . . . . . . . . . 971060

b) Eintreten, Begrüßen, Austausch von Visitenkarten, Sitzordnung . . . . . . . . . . . . . . . . . 981060

c) Aufwärmphase . . . . . . . . . . . . . . . . . . . . . . 1011061

d) Verhandlungsphase . . . . . . . . . . . . . . . . . . . . . . . 1021062

e) Abschluss der Verhandlung . . . . . . . . . . . . . . . . 1081063

3. Technische Besonderheiten . . . . . . . . . . . . . . 1091064

a) Witze und Humor . . . . . . . . . . . . . . . . . . . . . 1091064

b) Lachen . . . . . . . . . . . . . . . . . . . . . . . . . . . 1101064

c) Frauen im Verhandlungsteam . . . . . . . . . . . . . 1111064

d) Gestik und Körpersprache . . . . . . . . . . . . . . . 1121065

e) Einsatz von Dolmetschern . . . . . . . . . . . . . . . 1131065

f) Kommunikation von Reisedaten. . . . . . . . . . . . 1141066

g) Geschenke . . . . . . . . . . . . . . . . . . . . 1151066

h) Abendessen - Karaoke . . . . . . . . . . . . . . . . . . 1161067

i) Bankette . . . . . . . . . . . . . . . . . . . . . 1171068 
4. Taktik und Strategie . . . . . . . . . . . . . . . . . . 1181069

a) Eigene Taktik . . . . . . . . . . . . . . . . . . . . . . . . 1191070

aa) Zugeständnisse. . . . . . . . . . . . . . . . . . . . . 1191070

bb) Preise und Konditionen . . . . . . . . . . . . . . . . 1201070

cc) Ausloten kritischer Punkte . . . . . . . . . . . . . 1211070

dd) Herrschaft über Vertragstext . . . . . . . . . . . . . 1221070

ee) Bewertung von Angaben . . . . . . . . . . . . . . 1231071

ff) Sensible Fragen. . . . . . . . . . . . . . . . . . . . . 1241071

gg) Appell an Vertragstreue . . . . . . . . . . . . . . 1251071

hh) Inakzeptable Forderungen . . . . . . . . . . . . . . 1261071

ii) Patt-Situationen . . . . . . . . . . . . . . . . . . 1271072

ij) Einsatz der Hierarchie . . . . . . . . . . . . . . . 1281072

b) Chinesischer Verhandlungsstil und chinesische

Verhandlungstaktik . . . . . . . . . . . . . . . . 1291072

aa) Kommunikation außerhalb der offiziellen Verhandlungen . . . . . . . . . . . . . . . . . . . . 1291072

bb) Mangelnde Schriftlichkeit des Verfahrens . . . . . 1301073

cc) Geduld, Geduld, Geduld . . . . . . . . . . . . . . 1311073

dd) Wutausbrüche . . . . . . . . . . . . . . . . . . . . 1321074

ee) Plötzlicher Zeitdruck . . . . . . . . . . . . . . . . . 1331074

ff) Nachverhandlungen bei Unterschriftszeremonien 1341074

gg) Nachforderungen . . . . . . . . . . . . . . . . . 1351075

c) Lesen des Verhandlungsverlaufs . . . . . . . . . . . . . 1361075

aa) Verärgerung. . . . . . . . . . . . . . . . . . . . . 1371075

bb) Schweigen . . . . . . . . . . . . . . . . . . . 1381075

cc) Äußern von Befürchtungen als Argument . . . . . 1391076

dd) "Nein“" erkennen - „Nein" sagen . . . . . . . . . . 1401076

ee) Verzögerungen erkennen, vermeiden oder erzeugen $141 \quad 1076$

VI. Vertragsdurchführung . . . . . . . . . . . . . . . . . . . 1451077

1. Der geschriebene Vertrag und seine Durchführung . . 1451077

a) Beobachtung des Partners . . . . . . . . . . . . . . . . 1461077

b) Vorgeschobene Hinderungsgründe . . . . . . . . . . . . 1491078

2. Streit über Vertragserfüllung . . . . . . . . . . . . . . . . 1511078

a) Außergerichtliche und gerichtliche Auseinandersetzung. . . . . . . . . . . . . . . . . . 1511078

b) Typische Konfliktkonstellationen . . . . . . . . . . . 1541079

aa) Landnutzungsrechte/erforderliche Lizenzen . . . 1541079

bb) Zahlungsmoral . . . . . . . . . . . . . . . . . . . . 1551080

cc) Forderungsabschläge am Laufzeitende . . . . . . . 1561080 
3. Vertragsanpassung . . . . . . . . . . . . . . . . 1571080

4. Kündigung und/oder Beendigung des Vertrages . . . . . 1581081

5. Gerichtliche Hilfe . . . . . . . . . . . . . . . . . . . . . . 1601081

VII. Vertragscontrolling . . . . . . . . . . . . . . . . . 1621082

\section{4}

Verhandeln in Japan

(Tanaka)

I. Einführung . . . . . . . . . . . . . . . . . . . . . 11084

II. Japanische Rechtskultur _ . . . . . . . . . . . . . . $4 \quad 41085$

1. Religion . . . . . . . . . . . . . . . . . . . 51085

2. Geschichte . . . . . . . . . . . . . . . 91086

a) Taihō-ritsuryō-Kodex. . . . . . . . . . . . . . . . . 101086

b) Zeit der Shogunats-Regierung . . . . . . . . . . . . 111086

c) Meiji-Restauration . . . . . . . . . . . . . . . . . 131087

d) Nachkriegszeit . . . . . . . . . . . . . . . . . . . . . . 191089

3. Beispiele für Besonderheiten der japanischen

Rechtskultur . . . . . . . . . . . . . . . . 211090

4. Einflüsse der Rechtskultur auf die Unternehmenskultur $\quad 281092$

III. Vertragspraxis in Japan . . . . . . . . . . . . . . . . . 341095

1. Vertragsplanung . . . . . . . . . . . . . . . . . . . . . 341095

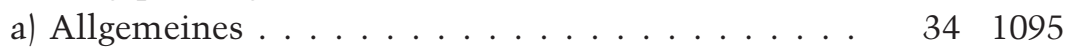

b) Juristen in Japan . . . . . . . . . . . . . . . . . . 371095

aa) Volljurist-Bengoshi. . . . . . . . . . . . . . . 371095

bb) Nicht-Volljuristen . . . . . . . . . . . . . . . 391096

(1) Juraschreiber (Shihō Shoshi) . . . . . . . . 411097

(2) Verwaltungsschreiber (Gyōsei Shoshi) … 421097

cc) Berater für ausländisches Recht (Gaikoku Hō

Jimu Bengoshi, sog. GJB) . . . . . . . . . . . 431097

dd) Notar (Kōshōnin) . . . . . . . . . . . . . . . . . . 441098

c) Auswahl von geeigneten Anwälten in Japan . . . . 451098

d) Nützliche Homepages . . . . . . . . . . . . . . . . . 481099

2. Vertragsdesign . . . . . . . . . . . . . . . . . . . . . . . . . . . 491099

a) Allgemeine Bemerkungen . . . . . . . . . . . . . . 491099

b) Anwendbares Recht . . . . . . . . . . . . . . . . . . . . 521101

c) Gerichtsstand . . . . . . . . . . . . . . . . . 531101

d) Schiedsklauseln . . . . . . . . . . . . . . . . . . 551102 
3. Vertragsverhandlungen . . . . . . . . . . . . . . . 561102

4. Vertragsabschluss . . . . . . . . . . . . . . . . . . . . 581103

a) Juristische Aspekte . . . . . . . . . . . . . . . . . . 591103

aa) Angebot . . . . . . . . . . . . . . . . . . . 601104

bb) Annahme . . . . . . . . . . . . . . . . . . . 611104

cc) Vertretungsberechtigte je nach Rechtsform . . . . 621105

b) Praktische Aspekte . . . . . . . . . . . . . . . . 651106

5. Vertragsdurchführung . . . . . . . . . . . . . 661106

6. Vertragsbeendigung . . . . . . . . . . . . . . . . 671107

7. Streitigkeiten hinsichtlich der Vertragsauslegung . . . . 691108

a) Allgemeines . . . . . . . . . . . . . . . . . . . . . . 691108

b) Die Rolle des Rechtsanwalts . . . . . . . . . . . . . . . 701108

c) Klage . . . . . . . . . . . . . . . . . . . . . . . . . . $71 \quad 1109$

d) Alternative Streitbeilegung . . . . . . . . . . . . . . . $74 \quad 1110$

aa) Schlichtungsverfahren (Chōtei) . . . . . . . . . . 741110

bb) Schiedsverfahren (Chūsai) . . . . . . . . . . . . . . . 761110

8. Vertragscontrolling . . . . . . . . . . . . . . 771111

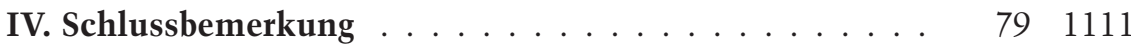

9.5

Verhandeln in Brasilien

(Curschmann)

1 Einführung

I. Erfolgreich in Brasilien . . . . . . . . . . . . . . . . . . 1a 1115

II. Geographische und wirtschaftliche Ausgangslage . . . 21116

III. Der Einfluss deutscher Einwanderer und Investoren . 31117

IV. Kulturelle und gesellschaftliche Kontraste $\ldots \ldots \ldots$. . 41118

\section{Vertragsplanung}

I. Brasilien und Deutschland: Die kulturellen Unterschiede $\quad 6 \quad 1120$

1. Die Gegensätze . . . . . . . . . . . . . . . . . 71120

2. Deutsche aus der Sicht der Brasilianer . . . . . . . . . . 991121

3. Brasilianer aus der Sicht der Deutschen . . . . . . . . 101122

II. Sprachprobleme . . . . . . . . . . . . . . . . . . . . . 121122 
III. Geistiges Eigentum/Markenpiraterie . . . . . . . . . . . 161123

IV. Informationen über den brasilianischen Partner/ Dokumentation . . . . . . . . . . . . 171124

\section{Vertragsdesign}

I. Geschriebenes Recht . . . . . . . . . . . . . . . . . . 191125

II. Rechtswirklichkeit . . . . . . . . . . . . . . . . . 201126

III. Vertragsstruktur und Vertragssprache . . . . . . . . . 231127

IV. Beglaubigung, Beurkundung, Formerfordernisse . . . . . 241128

\section{Vertragsverhandlung}

I. Verhandlungsatmosphäre . . . . . . . . . . . . . . 261129

1. Höflichkeit . . . . . . . . . . . . . . . . . 271130

2. Spontaneität und Improvisationsfähigkeit . . . . . . . . . . . . 281130

3. Brasilianischer Humor . . . . . . . . . . . . . . . . . . . . 291131

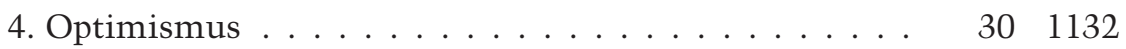

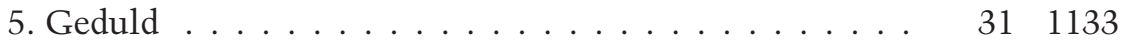

II. Der Zeitfaktor . . . . . . . . . . . . . . . . . . . . . . . . . 321133

1. Das brasilianische Verständnis von Zeit . . . . . . . . . . 321133

2. Unpünktlichkeit? Das Datum als ungefährer Zeitpunkt 331134

3. Das "Amanhã-Syndrom" . . . . . . . . . . . . . . 361135

4. Der Zeitunterschied "Fuso horario" . . . . . . . . . . 371136

III. Kleidung . . . . . . . . . . . . . . . . . . . . . 381136

IV. Rechtsanwälte . . . . . . . . . . . . . . . 391137

\section{Vertragsdurchführung}

I. Gute Verträge gewährleisten noch keine guten Resultate $41 \quad 1138$

1. Die Macht der persönlichen Beziehungen . . . . . . . . . 411138

2. Der "Jeitinho Brasileiro" . . . . . . . . . . . . . 421138

II. Die „Empresas de Serviços Paralegais“, die „Despachantes" und der Umgang mit Behörden 


\section{Vertragscontrolling \\ Rz. Seite \\ I. Das Erfordernis ständiger Kontaktpflege ～. . . . . . . . 441142 \\ II. Typische Gründe für Vertragsstörungen . . . . . . . . 451142}

7 Schlusswort $\ldots \ldots \ldots \ldots .46 \quad 1144$

9.6

Verhandeln in der Türkei

(Keki)

\section{Einführung}

I. Allgemeines zum Lande _ . . . . . . . . . . . . . . . . 11145

1. Hintergrundinformationen . . . . . . . . . . . . . . 11145

a) Geschichtlicher Rahmen . . . . . . . . . . . . . . 11145

b) Zur Entwicklung der türkischen Wirtschaft . . . . . . $4 \quad 1147$

c) Soziales Umfeld . . . . . . . . . . . . . . . . . . . . . . . 71148

d) Zur Kultur und Sprache . . . . . . . . . . . . . . . . . . 91149

2. Allgemeines zum türkischen Verhandlungspartner. . . 121150

3. Verhältnis des türkischen Verhandlungspartners zum deutschen Kulturkreis . . . . . . . . . . . . . . . . 171151

4. Steuerrechtliche Verstöße - ungeahnte Risiken? . . . . . 201152

5. Korruption . . . . . . . . . . . . . . . . . . . . . 271154

II. Zur Rechtsordnung im Allgemeinen . . . . . . . . . . . 281155

1. Entwicklungen im türkischen Recht . . . . . . . . . . . . 281155

2. Kritikpunkte . . . . . . . . . . . . . . . . 301156

3. Änderungen in der jüngeren Vergangenheit . . . . . . . $31 \quad 3156$

4. Stellung der Ausländer vor den Gesetzen . . . . . . . . 321157

\section{Vertragsmanagement}

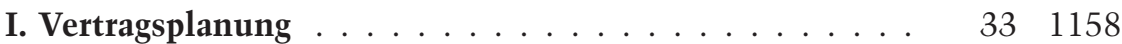

1. Einschaltung des Anwalts . . . . . . . . . . . . 331158

a) Der eigene Anwalt . . . . . . . . . . . . . . . . . 331158

b) Der Rechtsberater des türkischen Verhandlungspartners $38 \quad 1160$

2. Zugang zu Informationen . . . . . . . . . . . . . . . . 391161

a) Hinsichtlich der Türkei . . . . . . . . . . . . . . 391161 


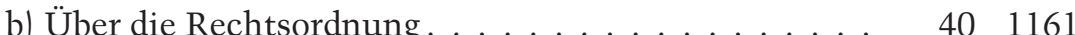

c) Über den jeweiligen Verhandlungspartner . . . . . . . 421162

3. Vorvertragliche Phase. . . . . . . . . . . . . . . 431163

a) Vorvertragliche Regelungsinstrumente . . . . . . . . 431163

b) Vorvertragliche Haftung . . . . . . . . . . . . . . . . . 461164

c) Vorbereitende Sicherung von Rechten . . . . . . . . . 481165

II. Vertragsdesign . . . . . . . . . . . . . . . . . . . . . . . . 501166

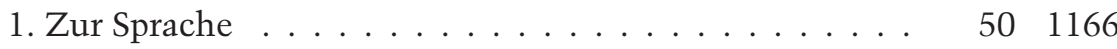

2. Struktur. . . . . . . . . . . . . . . . . . . . 531167

3. Vertragspartner und Haftungsfragen . . . . . . . . . 551167

4. Absicherung von Krediten an die türkische Partei . . . . 581168

5. Wahl des zuständigen Gerichts und des anwendbaren Rechts . . . . . . . . . . . . . . . . . . . 621169

III. Vertragsverhandlung . . . . . . . . . . . . . . . . . . . 651170

1. Sprachliche Barrieren . . . . . . . . . . . . . . . . . 651170

2. Publizierung von Verhandlungsergebnissen? . . . . . . $66 \quad 1171$

3. Einfluss von Drittparteien . . . . . . . . . . . . . . $67 \quad 67171$

4. Einfluss des Steuerrechts . . . . . . . . . . . . . . . . 701172

5. Psychologie. . . . . . . . . . . . . . . . . . . $71 \quad 7172$

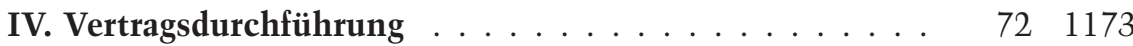

1. Unterzeichnung . . . . . . . . . . . . . . . . . . . . . . 721173

a) Die Unterschriften . . . . . . . . . . . . . . . . . . . $72 \quad$. . . . . . . . 73

b) Das Unterschriftenzirkular . . . . . . . . . . . . . . . . 731173

c) Die Stempelsteuer . . . . . . . . . . . . . . . . . . . . $74 \quad 1174$

2. Formvoraussetzungen und Beweisvorschriften . . . . . $77 \quad 1175$

3. Vertragserfüllung . . . . . . . . . . . . . . . . 791176

4. Der Erfüllungsanspruch ．.. . . . . . . . . . . . . 801176

5. Vollstreckung von Entscheidungen nichttürkischer Gerichte und Schiedsgerichte . . . . . . . . . . . . . 831177

V. Vertragscontrolling . . . . . . . . . . . . . . . . . . . 851177

VI. Quellen . . . . . . . . . . . . . . . . . . . . . . . . . . . 881178

1. Literatur . . . . . . . . . . . . . . . . . . . . . . . 881178

a) Allgemeine Literatur . . . . . . . . . . . . . . . . . 881178

b) Juristische Literatur . . . . . . . . . . . . . . . . . 891178

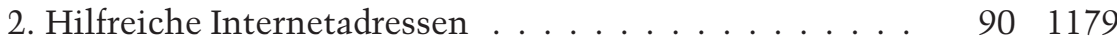

3. Zeitschriften . . . . . . . . . . . . . . . . . 911179

a) Deutsch . . . . . . . . . . . . . . . . . . . 911179

b) Englisch . . . . . . . . . . . . . . . . . . 921179 


\section{7}

Verhandeln in Indien

(Luthra)

\section{Einführung}

Rz. Seite

I. Ausgangslage

11181

II. Kulturelle, religiöse und soziologische Kontraste

Indiens . . . . . . . . . . . . . . . . . . . . 41183

1. Indien als „Vielvölkerstaat" - Pluralismus . . . . . . . 51183

2. Religionen und Glaubensrichtungen . . . . . . . . . . . 61184

3. Sprachen und Schriftsysteme . . . . . . . . . . . . . 71184

4. Das Kastenwesen . . . . . . . . . . . . . . . . 81185

5. Hierarchiesysteme als Kulturelement . . . . . . . . . 91185

6. Soziale Unterschiede . . . . . . . . . . . . . . . . . . . . . 101186

III. Wirtschaftslage Indiens _. . . . . . . . . . . . . . . 111186

1. Entwicklung . . . . . . . . . . . . . . . . . 111186

2. Aktuelle Kennzahlen . . . . . . . . . . . . . . . . . 121187

\section{Vertragsmanagement}

I. Vertragsplanung . . . . . . . . . . . . . . . . . . . . . . . . 141188

1. "Planning is essential“ . . . . . . . . . . . . . . . 141188

2. Wesentliche Elemente der Planung . . . . . . . . . . . . . 171189

3. Frühzeitige Auswahl geeigneter Berater . . . . . . . . . . 211191

4. Organisation von Reise und Reiseverlauf, Kleidung . . . 221192

5. Quellen der Informationsbeschaffung . . . . . . . . . . 281194

II. Vertragsdesign . . . . . . . . . . . . . . . . . . . . . . . . . . 291195

1. Vorabüberlegung . . . . . . . . . . . . . . . . . . . . 291195

2. Das Common Law als Grundlage für das indische Vertragsdesign ................. 301195

3. Besonderheiten des indischen Vertragsdesigns . . . . . . 311195

III. Vertragsverhandlung . . . . . . . . . . . . . . . . . . . . 361200

1. Grundlagen . . . . . . . . . . . . . . . . . 361200

2. Englisch als Verhandlungs- und Vertragssprache; das „indische Englisch" . . . . . . . . . . . . . 371200

3. Gestik, Mimik und Zeichensprache . . . . . . . . . . . 411202

4. Preisverhandlungen, Berechnungsmethodik, Zahlenwerk - "Lakhs und Crores" . . . . . . . . . . . . 421203 
5. Einigung und Nachverhandlung . . . . . . . . . . 431203

6. Erfahrungen zu Verhandlungen in Indien . . . . . . . 441204

IV. Vertragsdurchführung . . . . . . . . . . . . . . 46a 1205

1. Persönliche Präsenz vor Ort . . . . . . . . . . . . 471205

2. Arbeitskräfte, Arbeitstage und Arbeitszeiten, staatliche Feiertage, religiöse Feiertage und Feste sowie "Special Leave" . . . . . . . . . . . . . . . . . . . $48 \quad 1205$

3. "No problem", „Yes, we can do", „101 Percent", "Pakhar" . . . . . . . . . . . . . . . . . 501207

4. Korruption und "Speed Money" . . . . . . . . . . . . 511207

5. Devisenbewirtschaftung (teilweise) . . . . . . . . 521207

6. Streitbeilegung. . . . . . . . . . . . . . . . . . . 531208

V. Vertragscontrolling . . . . . . . . . . . . . . . . 541208

Teil 10

Qualitätsmanagement von Vertragsprojekten Typische Fehler von Managern im Umgang mit ihren Beratern aus Sicht des Beraters (Malik)

I. Berufsverständnis und Arbeitskontext _ . . . . . . . 21211

II. Fehler im Entscheidungsprozess . . . . . . . . . . . . 131214

1. Die präzise Bestimmung des Problems . . . . . . . . . 141214

2. Informationsmängel über Sachfragen des Unternehmens $\quad 17 \quad 1215$

3. Informationsmängel über Personen und die Funktionsweise der Organe . . . . . . . . . . . . . . . . 241217

4. Die Definition der Lösungsspezifikationen . . . . . . . 271218

5. Die Suche nach Alternativen . . . . . . . . . . . . . 311219

III. Typische Fehler in der Arbeitsweise . . . . . . . . . . 331219

1. Unkenntnis über die Informationsverarbeitungsgewohnheiten . . . . . . . . . . . . . . . $36 \quad \ldots 220$

2. Wirksame Berichte . . . . . . . . . . . . . . . 381221

IV. Fehlervermeidung als Aufgabe des Managers . . . . . $41 \quad 1222$ 


\section{Teil 11 \\ Checklisten}

\section{1 \\ Checklisten für Austauschverträge \\ (Pische1/Junker)}

I. Dienstvertrag für freie Mitarbeiter . . . . . . . . . . . 11225

II. Vertrag für Handelsvertreter . . . . . . . . . . . . . . 21228

III. Vertrag eines GmbH-Geschäftsführers . . . . . . . . . . 31234

IV. Mietvertrag über Gewerbeimmobilie . . . . . . . . . . 41238

V. Lizenz- und Know-how-Vertrag . . . . . . . . . . . . . . . 51244

\section{2}

Checklisten für Gesellschaftsverträge

(Knigge)

I. Gesellschaft bürgerlichen Rechts . . . . . . . . . . 11251

II. Gesellschaft mit beschränkter Haftung . . . . . . . 31259

III. Kommanditgesellschaft . . . . . . . . . . . . . . . . . 51269

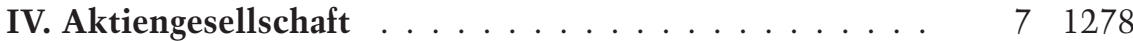

Verzeichnis der Autoren . . . . . . . . . . . . . . . . . . . . . . . . 1291

Sachregister . . . . . . . . . . . . . . . . . . . . . . . . . 1297 